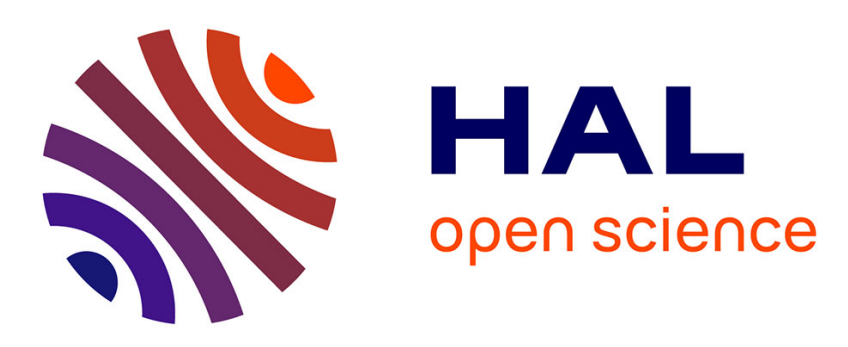

\title{
An updated experimental and kinetic modeling study of n-heptane oxidation
}

\author{
Kuiwen Zhang, Colin Banyon, John Bugler, Henry J. Curran, Anne
}

Rodriguez, Olivier Herbinet, Frédérique Battin Leclerc, Christine B'Chir, Alexander Karl

\section{To cite this version:}

Kuiwen Zhang, Colin Banyon, John Bugler, Henry J. Curran, Anne Rodriguez, et al.. An updated experimental and kinetic modeling study of n-heptane oxidation. Combustion and Flame, 2016, 172, pp.116-135. 10.1016/j.combustflame.2016.06.028 . hal-01349454

\section{HAL Id: hal-01349454 https://hal.science/hal-01349454}

Submitted on 27 Jul 2016

HAL is a multi-disciplinary open access archive for the deposit and dissemination of scientific research documents, whether they are published or not. The documents may come from teaching and research institutions in France or abroad, or from public or private research centers.
L'archive ouverte pluridisciplinaire HAL, est destinée au dépôt et à la diffusion de documents scientifiques de niveau recherche, publiés ou non, émanant des établissements d'enseignement et de recherche français ou étrangers, des laboratoires publics ou privés. 


\title{
An updated experimental and kinetic modeling study of $\boldsymbol{n}$-heptane oxidation
}

\author{
Kuiwen Zhang1, Colin Banyon'1, John Bugler1, Henry J. Curran'1, ${ }^{1}$, Anne Rodriguez ${ }^{2}$, \\ Olivier Herbinet ${ }^{2}$, Frédérique Battin-Leclerc ${ }^{2}$, Christine B'Chir ${ }^{3}$, Karl Alexander \\ Heufer $^{3}$ \\ 1 School of Chemistry, National University of Ireland Galway, Ireland \\ ${ }_{2}^{2}$ Laboratoire Réactions et Génie des Procédés, CNRS, Université de Lorraine, ENSIC, 1, rue Grandville, BP \\ 20451, 54001 Nancy Cedex, France \\ ${ }^{3}$ Physico-Chemical Fundamentals of Combustion (PCFC), RWTH Aachen University, Schinkelstr. 8, 52062 \\ Aachen, Germany
}

Published in Combustion and Flame (2016), 172, 116-135

doi:10.1016/j.combustflame.2016.06.028

\begin{abstract}
This work presents an updated experimental and kinetic modeling study of $n$-heptane oxidation. In the experiments, ignition delay times of stoichiometric $n$-heptane/air mixtures have been measured in two different high-pressure shock tubes in the temperature range of 726-1412 $\mathrm{K}$ and at elevated pressures (15, 20 and 38 bar). Meanwhile, concentration versus time profiles of species have been measured in a jet-stirred reactor at atmospheric pressure, in the temperature range of 500-1100 $\mathrm{K}$ at $\varphi=0.25,2.0$ and 4.0. These experimental results are consistent with those from the literature at similar conditions and extend the current data base describing $n$-heptane oxidation.

Based on our experimental observations and previous modeling work, a detailed kinetic model has been developed to describe $n$-heptane oxidation. This kinetic model has adopted reaction rate rules consistent with those recently developed for the pentane isomers and for $n$-hexane. The model has been validated against data sets from both the current work and the literature using ignition delay times, speciation profiles measured in a jet-stirred reactor and laminar flame speeds over a wide range of conditions. Good agreement is observed between the model predictions and the experimental data. The model has also been compared with several recently published kinetic models of $n$-heptane and shows an overall better performance. This model may contribute to the development of kinetic mechanisms of other fuels, as $n$-heptane is a widely used primary reference fuel. Since the sub-mechanisms of $n$-pentane, $n$-hexane and $n$-heptane have adopted consistent reaction rate rules, the model is more likely to accurately simulate the oxidation of mixtures of these fuels. In addition, the successful implementation of these rate rules have indicated the possibility of their application for the development of mechanisms for larger hydrocarbon fuels, which are of great significance for practical combustion devices.
\end{abstract}

Keywords: $n$-Heptane; Kinetic model; Oxidation; Shock tube; Jet-stirred reactor 


\section{Introduction}

The oxidation of $n$-heptane has been widely studied as it is a primary reference fuel (PRF) and is a representative normal alkane. It is also an important component of toluene reference fuel (TRF) and ethanol toluene reference fuel (ERF) [1], which has been used as a surrogate gasoline fuel for research of combustion processes in internal combustion engines [2]. Experiments have been performed which have focused on different properties of fuel oxidation over a wide range of conditions, such as ignition delay times in shock tubes [3-8] and rapid compression machines [9-12], species versus time and/or temperature profiles measured in jet-stirred reactors [13-17] and flow reactors [18-21], laminar flame speeds [22-26] and spatial distribution of species in flames [27-30]. Moreover, a series of experiments have been performed in engines [31-35] to study homogeneous charge compression ignition (HCCI), engine knock, exhaust gas recirculation (EGR), NOx emission control, etc. Since 1979 [4] efforts have been made to develop a kinetic model for $n$-heptane oxidation at both low temperature and high temperature to provide further insight into this process. In 1989, Westbrook et al. developed a detailed chemical kinetic mechanism to describe the oxidation of $n$-heptane and iso-octane [36]. This mechanism adopted both low- and high-temperature chemistry, and was validated through comparisons with experimental data from shock tube, turbulent flow reactor and jet-stirred reactors. Later, Chevalier developed a computational technique to automatically develop detailed kinetic mechanisms, which were used to study the influence of fuel, fuel mixtures and fuel additives on knock tendency [37]. Ranzi et al. proposed a semi-detailed kinetic model for $n$-heptane oxidation [38], while Côme used a computer package to develop the kinetic models for the oxidation of both $n$-heptane and iso-octane [39].

Curran et al. [40] carried out a comprehensive kinetic modeling study of $n$-heptane oxidation in a systematic way. The important reactions during the oxidation of $n$-heptane were categorized into 25 different reaction classes, including 10 reaction classes to describe high-temperature oxidation and 15 classes to describe the low-temperature regime. Although approximate treatments were assigned to some less important reactions such as the consumption of the heptene isomers, the overall performance of the mechanism was very good. This mechanism has been improved and further validated, with good performance over the pressure range of 3 to $50 \mathrm{~atm}$, in the temperature range of 650 to $1200 \mathrm{~K}$ and at equivalence ratios of 0.3 to 2.0. More importantly, this model set a successful frame for the kinetic mechanism development of other larger $n$-alkanes [41]. A more recent study carried out by Mehl et al. [42] on the kinetic modeling of gasoline surrogate components and mixtures under engine conditions has further refined and adopted this mechanism. Moreover, this mechanism also forms the basis for the mechanism development in this work.

There has been a continual interest among the research community in developing a better understanding of $n$-heptane oxidation both experimentally and theoretically. For example, Herbinet et al. performed an experimental study in a jet-stirred reactor [16]. In addition to traditional gas chromatography, the experiments also used synchrotron vacuum ultraviolet photoionization mass spectrometry as the diagnostic technique to identify the unstable species such as radicals, which is an example of the new experimental methods being applied to this kind of study. Herbinet et al. also generated a kinetic mechanism using the software EXGAS [43], which satisfactorily reproduced the mole fraction profiles of most of the species identified in the experiments.

Meanwhile, new reaction pathways are being adopted into the kinetic model to better describe the oxidation process of $n$-heptane. Recently, Pelucchi et al. proposed an improved kinetic model for $n$-heptane [44], by emphasizing new reaction classes producing organic acids, diones and ketones in the low temperature regime. The mechanism was validated over a wide range of conditions including both low and high-temperature ranges. Good agreement was observed between simulations and experimental data from the literature for ignition delay time measurements $[5,42,45]$, species profiles measurements taken in a jet-stirred reactor [14-16] and in a flow reactor [20], as well as 
laminar flame speeds [26]. Meanwhile, the experimental database of $n$-heptane is being extended to cover a wider range of conditions. Seidel et al. performed an experimental and kinetic modeling study of a fuel-rich, premixed $n$-heptane flame at 40 mbar, and successfully identified over 80 species generated at this condition [30]. Based on previous work, a detailed kinetic model was developed. Reduced kinetic mechanisms are also being proposed, such as the work by Cai and Pitsch [46], who proposed an optimized chemical mechanism for gasoline surrogates which was validated under extensive conditions and it showed a very good performance compared to experimental ignition delay measurements.

This current study is based on a continuity of effort in experimental and kinetic modeling studies of hydrocarbon fuels that we have published previously [47-58]. In this work, the ignition delay times of $n$-heptane in air are firstly measured in two different high-pressure shock tubes to provide more experimental ignition delay time data at elevated pressures. Moreover, the experimental conditions of $n$-heptane oxidation in a jet-stirred reactor have been extended to extremely rich $(\varphi=4.0)$ and very lean $(\varphi=0.25)$ conditions, while the other conditions remain consistent with those published previously. To reflect the improvements in the chemical kinetics and thermodynamics as well as their impact, a detailed kinetic model of $n$-heptane oxidation has been developed based on our previous work, including our updated base mechanism [47-50,53,56-58], the sub-mechanisms of the pentane isomers [51,55] and $n$-hexane [54]. In the development of this mechanism, the new reaction classes and reaction rate rules with modifications, which have been successfully applied to the pentane isomers and $n$-hexane, have been adopted. The thermodynamic database has also been updated with recently published optimized group values [52]. The model has been validated using the experimental data sets obtained in this work, as well as those from the literature for ignition delay times, species profile measured in jet-stirred reactors and also for laminar flame speed measurements. Moreover, comparisons are made between the current model and those from recent publications. The significant reaction pathways for the oxidation of $n$-heptane are revealed by further analysis of the simulations.

\section{Experimental methods}

\subsection{PCFC shock tube}

The Physico-Chemical Fundamentals of Combustion (PCFC) shock tube at Aachen University has been designed similar to the high-pressure shock tube at NUIG. It has an inner diameter of $63.5 \mathrm{~mm}$ and an overall length of about $7.5 \mathrm{~m}$ with a $3 \mathrm{~m}$ driver section. Due to physical space limitations the driver section is curved with a bending radius of $1 \mathrm{~m}$. The diaphragm section can house up to two pre-scored aluminum diaphragms. All parts coming into contact with fuel/air mixtures are made of stainless steel (316Ti), except for the aluminum diaphragms. Shock velocities and pressure profiles are recorded in the measuring section close to the endwall of the driven section with up to 8 PCB 113B22 pressure sensors. Signals are recorded using a digital oscilloscope with a sampling rate of $25 \mathrm{MHz}$. Fuel/air mixtures are prepared in a separate $40 \mathrm{~L}$ Teflon coated stainless steel mixing vessel. Partial pressures are used to prepare the desired gas mixtures. Static pressures are monitored with two STS ATM. 1st pressure sensors with measuring ranges of 500 mbar and 5 bar, respectively. The shock tube, manifold and mixing vessel can be electrically heated to $150{ }^{\circ} \mathrm{C}$ in order to avoid fuel condensation. In this study, initial temperatures of $40{ }^{\circ} \mathrm{C}$ are sufficient due to the relatively high vapor pressure of $n$-heptane. Temperatures are monitored with type $\mathrm{T}$ thermocouples due to their lower measuring uncertainty compared to conventional type $\mathrm{K}$ ones. High purity grade gases for reactive mixture preparation $\left(\mathrm{N}_{2}\right.$ and $\left.\mathrm{O}_{2}\right)$ were provided from Praxair and Westfalia. Helium and compressed air were used as driver gases. The reflected shock conditions were calculated using the initial conditions of pressure and temperature and mixture composition and the measured shock velocity with an in-house code which is based on the shock and detonation toolbox [59] in Cantera [60]. An uncertainty analysis has been performed for the PCFC shock tube and is provided as Supplementary material. Maximum uncertainties in the reflected shock temperatures are estimated to 
amount to $1.1 \%$ in the reflected shock temperature and 3.5\% in the reflected shock pressure. Depending on the fuel reactivity this can induce uncertainties of up to $15 \%$ in the measured ignition delay time for the range studied.

\subsection{NUIG shock tube}

High-temperature (above $1000 \mathrm{~K}$ ) ignition delay times for stoichiometric mixtures of $n$-heptane at compressed pressures of 15 bar in a $21 \% \mathrm{O}_{2}: 79 \% \mathrm{~N}_{2}$ bath gas were measured in the National University of Ireland, Galway (NUIG) high-pressure shock tube [61], with an inner diameter of $63 \mathrm{~mm}$. The methodology used to measure ignition delay times in this facility has recently been described in our work on $n$-hexane [54], and thus will not be described further here. Again, $n$-heptane was supplied by TCI UK in high purity (>99.0\%), while oxygen (99.5\%) and nitrogen (99.95\%) were supplied by BOC Ireland.

\subsection{Jet-stirred reactor}

The oxidation of $n$-heptane was studied in a jet-stirred reactor at LRGP in Nancy (France). This reactor can be considered to be perfectly stirred [62] and has frequently been used for numerous gas phase kinetic oxidation studies of hydrocarbons and oxygenated compounds [63]. Experiments were performed at a constant pressure of $1.067 \mathrm{bar}$, at a residence time of $2 \mathrm{~s}$, at temperatures ranging from 500 to $1100 \mathrm{~K}$, and at four equivalent ratios of $\varphi$ $=0.25,1.0,2.0$ and 4.0. The fuel was diluted in helium resulting in an $n$-heptane concentration of $0.5 \%$. The fuel was provided by Sigma-Aldrich (purity of 99\%). Helium and oxygen were provided by Messer with purities of $99.99 \%$ and $99.999 \%$, respectively.

The reactor is made of fused silica, and consists of a fused silica sphere (volume $=95 \mathrm{~cm}^{3}$ ) into which diluted reactant enters through an injection cross located at its center. It is operated at constant temperature and pressure and it is preceded by an annular pre-heating zone in which the temperature of the gases is increased to the reactor temperature before entering it. The gas mixture residence time inside the annular pre-heater is very short compared to its residence time inside the reactor (a few percent). Both the spherical reactor and the annular pre-heating zone are heated using resistance wires coiled around their walls. The temperature is controlled using type $\mathrm{K}$ thermocouples. The reaction temperature was measured using another independent type $\mathrm{K}$ thermocouple which was located in a glass finger at the center of the reactor (which is actually the intra annular part of the preheater). The uncertainty in the temperature measurement is $\pm 5 \mathrm{~K}$.

A Coriolis flow controller is used to feed $n$-heptane, and two mass flow controllers are used to meter the helium and oxygen flow rates. The fuel is mixed with helium and evaporated in a heat exchanger. Oxygen is added at the reactor inlet. The accuracy in flow rates given by the manufacturer (Bronkhorst) is $0.5 \%$. This results in a small uncertainty of $2.00 \pm 0.01 \mathrm{~s}$ in the residence time.

Product species are analyzed directly by gas chromatography using a heated transfer line between the reactor outlet and the chromatograph sampling. The temperature of the line is heated to $160^{\circ} \mathrm{C}$ to avoid product condensation during transfer. Three gas chromatographs are used for the quantification of the different species. The first chromatograph, equipped with a Carbosphere packed column, a thermal conductivity detector (TCD) and a flame ionization detector (FID), is used for the quantification of $\mathrm{O}_{2}, \mathrm{CO}, \mathrm{CO}_{2}$, methane, ethylene, acetylene and ethane. The second is fitted with a PlotQ capillary column, a methanizer, and an FID is used for the quantification of molecules from methane to reaction products containing up to 5 carbon atoms and 1 or 2 oxygen atoms maximum. The third is fitted with a HP-5 capillary column and an FID is used for the quantification of molecules which contain at least 5 carbon atoms. Calibrations are performed by injecting standards where available or by using the effective carbon 
number method when standards were unavailable. The maximum relative error in mole fractions is estimated to be $\pm 5 \%$ for species which are calibrated using standards and $\pm 10 \%$ for species calibrated using the effective carbon number method $[64,65]$. The identification of reaction products is performed using a gas chromatograph equipped with a PlotQ or an HP-5 capillary column and coupled to a mass spectrometer (quadrupole). The mass spectra of all of the detected reaction products are included in the NIST 08 Mass Spectra Database [66]. For certain species, singlephoton-ionization mass spectrometry (SPI-MS) [67] is used for higher accuracy, as shown in the experimental data sets provided in the Supplementary material.

\section{Chemical kinetic mechanism}

The kinetic model used in this work consists of 1268 species and 5336 reactions. The sub-mechanism for $\mathrm{C}_{0}-\mathrm{C}_{4}$ fuels is taken from AramcoMech 2.0 [57,58]. This mechanism has been widely validated for a series of fuels including hydrogen, syngas [48], methane, methanol [56], formaldehyde, ethane, ethylene, acetylene, ethanol, acetaldehyde [47], dimethyl ether [53] and propene [49,50]. The sub-mechanisms for the three pentane isomers and for $n$-hexane have also been published recently $[51,54,55]$. On the basis of the above mechanisms, an $n$-heptane sub-mechanism has been developed in this work. Table 1 shows the nomination of some representative species in the $n$-heptane sub mechanism.

Table 1: Nomination of some representative species in $n$-heptane sub mechanism.

$$
\begin{gathered}
\mathrm{nC}_{7} \mathrm{H}_{16} \\
\dot{\mathrm{C}}_{7} \mathrm{H}_{15}-1 \\
\mathrm{C}_{7} \mathrm{H}_{14}-1 \\
\mathrm{C}_{7} \mathrm{H}_{15} \dot{\mathrm{O}} 2-2 \\
\dot{\mathrm{C}}_{7} \mathrm{H}_{14} \mathrm{OOH} 2-4 \\
\mathrm{C}_{7} \mathrm{H}_{14} \mathrm{O} 2-5 \\
\mathrm{C}_{7} \mathrm{H}_{14} \mathrm{OOH} 2-4 \dot{\mathrm{O}}_{2} \\
\dot{\mathrm{C}}_{7} \mathrm{H}_{13} \mathrm{Q} 13-5 \\
\mathrm{C}_{7} \mathrm{KET} 1-3
\end{gathered}
$$$$
\mathrm{C}_{7} \text { KET1-30 }
$$<smiles>CCCCCCC</smiles><smiles>C=CCCCCC</smiles><smiles>CCCCCC(C)[O-]</smiles><smiles>CCCCCC(C)O</smiles><smiles>CCC1CCC(C)O1</smiles><smiles>CCCC(CC(C)O)[O+]([O-])O</smiles><smiles>CCCCC(C)CCC</smiles>

$\mathrm{OOH} \mathrm{OOH}$<smiles>CCCCC(O)CCCC(O)CC=O</smiles> 
Figure 1 shows the reaction pathways for $n$-heptane oxidation considered in this work, which are similar to those considered previously [40,51,54]. The reaction pathways of a fuel are strongly dependent on its structure, and significantly affect the reactivity of the fuel. Compared to smaller alkanes, $n$-pentane shows a higher reactivity at low temperatures because its structure contains more connected secondary carbons. H-atom abstraction is favored at secondary sites compared to primary ones, where secondary pentyl peroxyl radicals formed can isomerize via six-membered transition state (TS) rings into hydroperoxy pentyl radicals. Six-membered TS ring formations are faster than any other (5-, 7-, or 8-membered ones) which is mainly due to their lower ring-strain energies and formation of six-membered TS ring structures contributes considerably to the chain branching process at low temperatures, promoting fuel reactivity $[51,54,55]$. Similarly, $n$-hexane shows a higher reactivity compared to $n$-pentane because six-membered TS ring structures are available for all of the four connected secondary carbons, while the reactivity of $n$-heptane is even higher than that of $n$-hexane since the ratio of secondary carbon atoms to primary ones is even higher again. However, the reaction pathways that need to be considered for $n$-pentane, $n$-hexane and $n$-heptane are almost identical, as shown in Figure 1. Therefore consistent reaction rate rules can be applied to their sub-mechanisms.

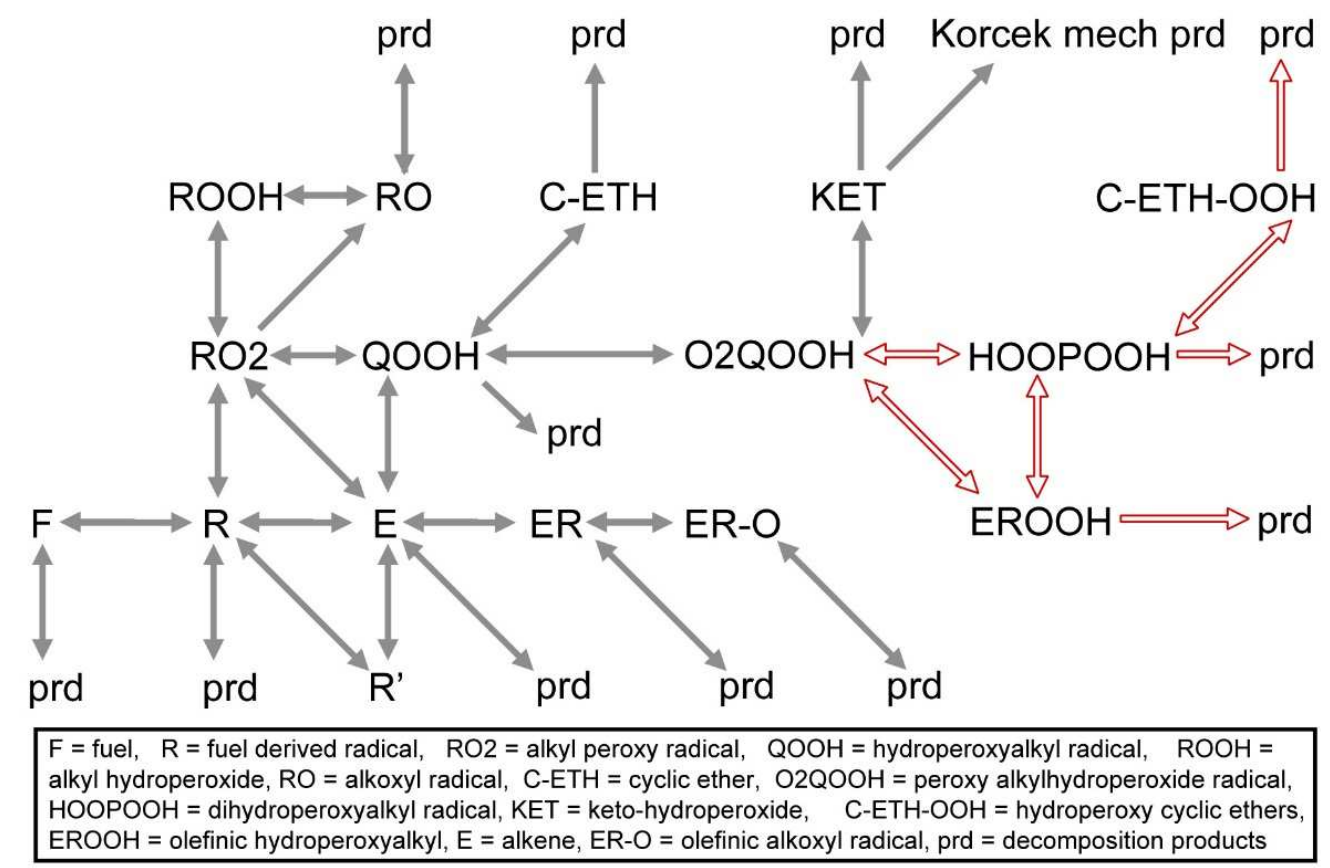

Figure 1: Reaction pathways considered in the model development of this work. The reaction pathways induced by the alternative isomerization of peroxy hydroperoxyalkyl have been marked with open arrows.

A series of reaction rate rules have been adopted in our previous work on the oxidation of the pentane isomers $[51,55]$. These rate rules were derived from recently published ab-initio calculations $[68,73]$ and have been applied to the reaction classes in the low temperature regime. New reaction classes related to the alternative isomerization pathway of peroxy hydroperoxyl alkyl radicals [51] have also been added. The mechanisms for the three pentane isomers predict well ignition delay times with good agreement observed compared to the experimental data [55]. Many of the rate constants for the low temperature reaction classes (e.g. $\mathrm{RO}_{2} \rightleftharpoons \mathrm{Q}^{\prime} \mathrm{OOH}$, etc.) for the pentane isomers are available from ab-initio calculations $[68,71,72]$, but those for the hexane isomers and larger alkanes are rare. Therefore in the kinetic modeling study of $n$-hexane, the reaction rate rules were derived from those calculated for $n$-pentane but modifications were made within their uncertainty range, which have led to better agreement between the experimental and simulated results [54]. The refined rate rules have been used to generate the $n$-heptane mechanism used in this work to maintain consistency in the chemical kinetics. 
The thermodynamic data of the species involved have been updated using the THERM software [74], which is based on the group additivity method proposed by Benson [75]. The group values used in the calculation have been optimized [52], and are consistent with those used for the pentane isomers and for $n$-hexane [51,54,55]. The kinetic mechanism, thermodynamic data, transport data, species glossary and group values for group additivity method are available as Supplementary material. In the future, this mechanism might be updated for better performance and released with comprehensive validations. Please visit our website http://c3.nuigalway.ie/ for more details.

\subsection{High temperature mechanism}

The most significant reaction classes in the high temperature regime of $n$-heptane oxidation are the unimolecular decomposition of the fuel and fuel derived radicals in addition to hydrogen abstraction from the fuel by the radical pool. To derive the rate constants for the unimolecular decomposition of $n$-heptane, firstly the high-pressure limit rate constants of the radical recombination are estimated; then the reverse rate constants are obtained using the CHEMRev software package [76] with their pressure dependence calculated using Quantum-Rice-RamspergerKassel/Modified Strong Collision (QRRK/MSC) theory, which has been proven to show good agreement with the more precise Rice-Ramsperger-Kassel-Marcus/Master Equation (RRKM/ME) approach for alkane decomposition [77]. The Lennard-Jones parameters for $n$-heptane are from Jasper and Miller [78], which are $\sigma=4.42 \AA$ and $\varepsilon=213$ $\mathrm{cm}^{-1}$ in a bath gas of $\mathrm{N}_{2}$. The pressure dependent rate constants for the decomposition of the fuel-derived radicals: $\dot{\mathrm{C}}_{7} \mathrm{H}_{15}-1, \dot{\mathrm{C}}_{7} \mathrm{H}_{15}-2$ and $\dot{\mathrm{C}}_{7} \mathrm{H}_{15}-3$ are adopted from [79].

$\mathrm{H}$-atom abstraction from the fuel by $\mathrm{OH}$ radicals is the most significant reaction class involving the fuel with the radical pool over a wide temperature range. The rate constants for these reactions have been adopted from the values reported by Sivaramakrishnan and Michael [80], who measured these reaction rates experimentally in a shock-tube using ÖH-radical electronic absorption and compared the results with literature data. $\mathrm{H}$-atom abstraction by $\mathrm{HO}_{2}$ radicals contributes little to fuel consumption at low temperatures (600-750 K) but these reactions become more important at higher temperatures (750-1300 K) because the $\mathrm{H}_{2} \mathrm{O}_{2}$ molecule produced decomposes into two $\dot{\mathrm{OH}}$ radicals, greatly promoting reactivity. The rate constants for $\mathrm{H}$-atom abstraction from the fuel by $\mathrm{HO}_{2}$ radicals are adopted from [81]. Other reactions in the high temperature regime and their rate constants are mainly derived from the $n$-heptane mechanism proposed by Curran et al. [40].

\subsection{Low temperature mechanism}

The low-temperature reaction pathways are illustrated in the upper part of Figure 1. In the low-temperature regime, the fuel derived radicals $(\dot{\mathrm{R}})$ add to molecular oxygen to form alkylperoxy radicals $\left(\mathrm{RO}_{2}\right)$. Further isomerization of $\mathrm{RO}_{2}$ via ring transition states and internal hydrogen atom transfer leads to the formation of hydroperoxy-alkyl radicals $\left(\mathrm{Q}^{\circ} \mathrm{OOH}\right)$. The most important competing reaction class is the concerted elimination forming $\mathrm{C}_{7}$ olefins and $\mathrm{HO}_{2}$ radicals, which becomes more competitive as the temperature increases. At low- and intermediatetemperatures this concerted elimination reaction tends to reduce reactivity, because it consumes a reactive radical (usually $\dot{\mathrm{OH}}$ ) in the hydrogen abstraction reaction from the fuel, and produces an $\mathrm{HO}_{2}$ radical which is less reactive. Other consumption reactions of $\mathrm{RO}_{2}$ are bi-molecular reactions, but only play a minor role in the reaction flux. For the consumption of $\mathrm{Q} \mathrm{OOH}$ radicals, the addition to molecular oxygen is a significant step, producing peroxy alkylhydroperoxide radicals $\left(\dot{\mathrm{O}}_{2} \mathrm{QOOH}\right)$ as the precursor of ketohydroperoxides. $\mathrm{OH}$ radicals are produced from both the formation and decomposition of ketohydroperoxides, which makes this reaction sequence the major chain branching process at low temperatures. Meanwhile, the consumption of Q $\mathrm{OOH}$ radicals also has other channels. As the $\mathrm{O}-\mathrm{O}$ bond in the hydroperoxy group is weak, the consumption of $\mathrm{Q}^{\circ} \mathrm{OOH}$ radical can produce small molecule 
products or cyclic ethers and release an $\mathrm{OH}$ radical, which contributes to the chain propagation process. The betascissions of $\mathrm{C}-\mathrm{O}$ bonds that produce olefins and $\mathrm{HO}_{2}$ radicals are only available for certain structures such as $\mathrm{C}_{7} \mathrm{H}_{14} \mathrm{OOH} 1-2$ and are thus less important.

The equilibrium between $\mathrm{RO}_{2}$ and $\mathrm{Q}^{\circ} \mathrm{OOH}$ radicals significantly influences fuel reactivity at low- and intermediatetemperatures. The concerted elimination reaction of $\mathrm{RO}_{2}$ leads to chain propagation while the addition of $\mathrm{Q}^{\circ} \mathrm{OOH}$ radicals to $\mathrm{O}_{2}$ ultimately contributes to chain branching. Other significant reaction classes that can affect this equilibrium include the addition of $\dot{\mathrm{R}}$ to $\mathrm{O}_{2}$, the formation of cyclic ethers and the formation of ketohydroperoxides. The modified reaction rate rules for the above mentioned reaction classes are consistent with those proposed for $n$-hexane [54], as shown in Table 2. Detailed discussions of the comparison of rate rules and the refinements can be found elsewhere [51].

Table 2: Modifications to the reaction rate rules.

\begin{tabular}{|c|c|c|c|}
\hline Reaction & $\begin{array}{l}\text { Rate } \\
\text { rules }\end{array}$ & Details & Example \\
\hline \multirow[t]{4}{*}{$\mathrm{RO}_{2} \rightleftharpoons \dot{\mathrm{QOOOH}}$} & \multirow{4}{*}{$\begin{array}{c}\text { Table } 6 \\
\text { in } \\
{[68]}\end{array}$} & \multicolumn{2}{|c|}{ A $\times 0.5$ for those using nearest analogy, which were not calculated: } \\
\hline & & $\begin{array}{l}5 \text { member ring, } \mathrm{O}_{2} \text { on secondary, } \\
\text { abstraction on primary }\end{array}$ & $\mathrm{C}_{7} \mathrm{H}_{15} \dot{\mathrm{O}}_{2}-2 \rightleftharpoons \dot{\mathrm{C}}_{7} \mathrm{H}_{14} \mathrm{OOH} 2-1$ \\
\hline & & $\begin{array}{l}7 \text { member ring, } \mathrm{O}_{2} \text { on secondary, } \\
\text { abstraction on secondary }\end{array}$ & $\mathrm{C}_{7} \mathrm{H}_{15} \dot{\mathrm{O}}_{2}-2 \rightleftharpoons \dot{\mathrm{C}}_{7} \mathrm{H}_{14} \mathrm{OOH} 2-5$ \\
\hline & & $\begin{array}{l}8 \text { member ring, } \mathrm{O}_{2} \text { on secondary, } \\
\text { abstraction on primary }\end{array}$ & $\mathrm{C}_{7} \mathrm{H}_{15} \dot{\mathrm{O}}_{2}-2 \rightleftharpoons \dot{\mathrm{C}}_{7} \mathrm{H}_{14} \mathrm{OOH} 2-6$ \\
\hline \multirow{6}{*}{$\begin{array}{l}\text { Cyclic ether } \\
\text { formation }\end{array}$} & \multirow{6}{*}{$\begin{array}{l}\text { Table } 3 \\
\text { in [72] }\end{array}$} & All A factors $\times 0.5$ & \\
\hline & & Ea+1 kcal for: & \\
\hline & & $\begin{array}{l}\mathrm{CY} / \mathrm{C} 4 \mathrm{O}, \mathrm{OOH} \text { on primary, radical on } \\
\text { secondary }\end{array}$ & $\dot{\mathrm{C}}_{7} \mathrm{H}_{14} \mathrm{OOH} 1-4<=>\mathrm{C}_{7} \mathrm{H}_{14} \mathrm{O} 1-4+\dot{\mathrm{O}} \mathrm{H}$ \\
\hline & & $\begin{array}{l}\mathrm{CY} / \mathrm{C} 30, \mathrm{OOH} \text { on secondary, radical } \\
\text { on secondary }\end{array}$ & $\dot{\mathrm{C}}_{7} \mathrm{H}_{14} \mathrm{OOH} 2-4<=>\mathrm{C}_{7} \mathrm{H}_{14} \mathrm{O} 2-4+\dot{\mathrm{O}} \mathrm{H}$ \\
\hline & & Ea-1 kcal for: & \\
\hline & & $\begin{array}{l}\mathrm{CY} / \mathrm{C} 40, \mathrm{OOH} \text { on secondary, radical } \\
\text { on secondary }\end{array}$ & $\dot{\mathrm{C}}_{7} \mathrm{H}_{14} \mathrm{OOH} 2-5<=>\mathrm{C}_{7} \mathrm{H}_{14} \mathrm{O} 2-5+\dot{\mathrm{O}} \mathrm{H}$ \\
\hline \multirow{4}{*}{$\begin{array}{l}\text { Concerted } \mathrm{HO}_{2} \\
\text { elimination }\end{array}$} & \multirow{4}{*}{$\begin{array}{l}\text { Table } 4 \\
\text { of }[71]\end{array}$} & $A \times 1.5$ for: & \\
\hline & & $\mathrm{O}_{2}$ on primary, $\mathrm{H}$ on secondary & $\mathrm{C}_{7} \mathrm{H}_{15} \dot{\mathrm{O}}_{2}-1<=>\mathrm{C}_{7} \mathrm{H}_{14}-1+\mathrm{HO}_{2}$ \\
\hline & & $\mathrm{O}_{2}$ on secondary, $\mathrm{H}$ on primary & $\mathrm{C}_{7} \mathrm{H}_{15} \dot{\mathrm{O}}_{2}-2<=>\mathrm{C}_{7} \mathrm{H}_{14}-1+\mathrm{HO}_{2}$ \\
\hline & & $\begin{array}{l}\mathrm{O}_{2} \text { on } \mathrm{S} 11, \mathrm{H} \text { on } \mathrm{S} 11 . \\
(\mathrm{P} 1-\mathrm{S} 10-\mathrm{S} 11-\mathrm{S} 11-\mathrm{S} 10-\mathrm{P} 1)\end{array}$ & $\mathrm{C}_{7} \mathrm{H}_{15} \dot{\mathrm{O}}_{2}-3<=>\mathrm{C}_{7} \mathrm{H}_{14}-3+\mathrm{HO}_{2}$ \\
\hline $\begin{array}{l}\text { Second addition to } \\
\qquad \mathrm{O}_{2}\end{array}$ & $\begin{array}{c}\text { Table IV } \\
\text { of [69] }\end{array}$ & $\mathrm{A} \times 0.5$ from the first addition to $\mathrm{O}_{2}$ & $\dot{\mathrm{C}}_{7} \mathrm{H}_{14} \mathrm{OOH} 1-2+\mathrm{O}_{2}<=>\mathrm{C}_{7} \mathrm{H}_{14} \mathrm{OOH} 1-2 \dot{\mathrm{O}}_{2}$ \\
\hline
\end{tabular}

The red open arrows in Figure 1 denote the reaction classes induced by the alternative isomerization pathways of $\dot{\mathrm{O}}_{2} \mathrm{QOOH}$ radicals. These reaction classes have been proposed in our previous work [51,54], with their reaction rate constants taken by analogy with those possible for $\mathrm{RO}_{2}$ radicals. Although the adoption of alternative isomerization pathways has proven to have a limited effect upon model predictions for $n$-hexane [54], these reaction classes have been included for $n$-heptane to reflect the complexity of the low temperature chemistry, which become more important for the oxidation of branched alkanes [51]. 


\section{Results and discussion}

\subsection{High pressure shock tube data}

The ignition delay times for the oxidation of stoichiometric $n$-heptane/air mixtures at different pressures have been measured in the PCFC high pressure shock tube, see solid symbols in Figure 2, over the temperature range of 688$1412 \mathrm{~K}$, which includes the low, intermediate and high temperature regimes. The new data sets are consistent with those reported in previous work $[82,83]$ which are depicted as half-filled symbols and open symbols respectively, showing a significant pressure effect reflected by the decrease in ignition delay times and the shifting of the negative temperature coefficient (NTC) region towards higher temperatures [5] at higher pressures. Furthermore, simulation results using the kinetic mechanism presented in this study are shown. Shock tube ignition delay times are simulated using the constant volume closed homogenous batch reactor code in CHEMKIN PRO [84]. It is assumed that the changes in conditions induced by facility effects in the region near the endwall can be treated as an isentropic compression/expansion by an effective volume change as in the RCM. These CHEMKIN PRO input files and the experimental data are available as Supplementary material. In the following descriptions, the ignition event in the simulation is defined as the maximum pressure rise unless the experimental data sets taken from literatures define the ignition delay differently.

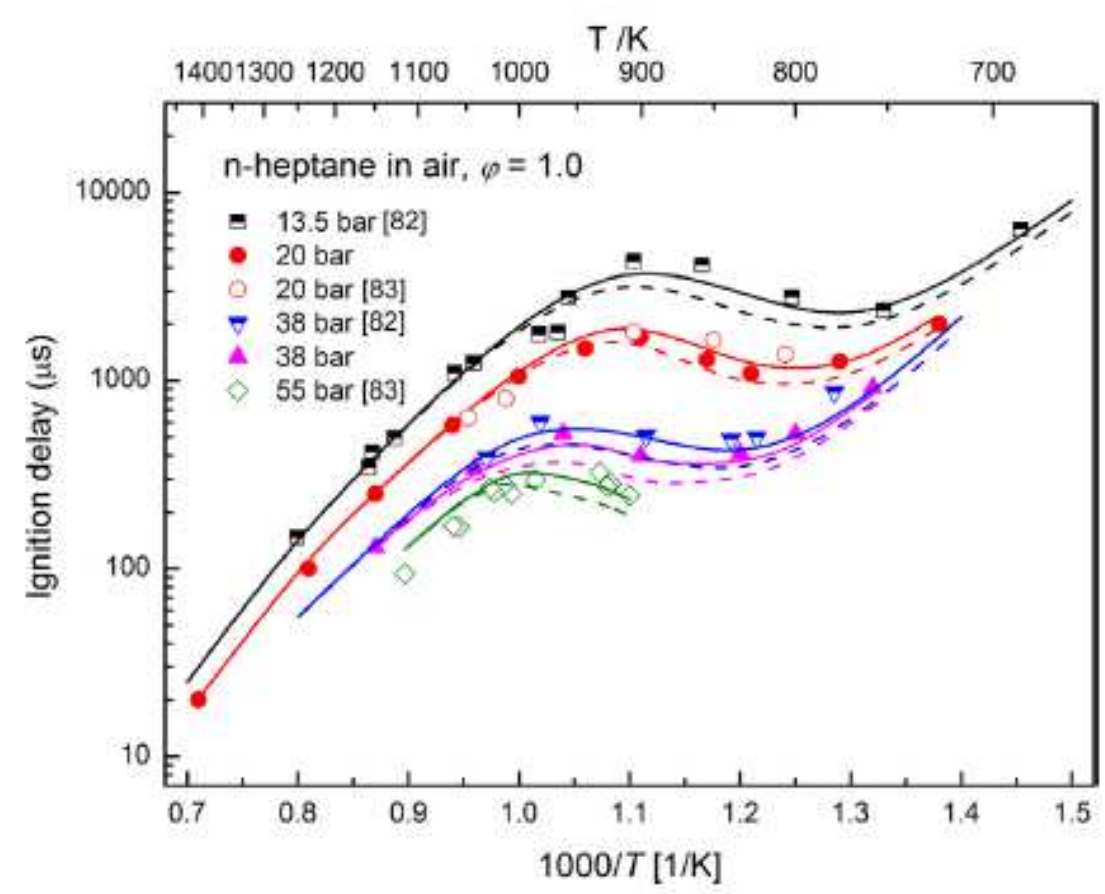

Figure 2: Experimental (symbols) and modeling results (lines) for $n$-heptane ignition delay times at multiple conditions (in air, $\varphi=1.0$ ). Half-filled symbols are experimental data from [82], while solid symbols are experimental data measured in this work. Open symbols are experimental data from [83]. Solid and dashed lines are predictions with and without the modifications in the rate rules, respectively.

It is important to note that the different data sets have been obtained in different facilities. This is a critical aspect regarding the level of confidence of the experimental results. By considering results taken at the same conditions but from different facilities, a higher level of confidence can be attributed to the experimental results. This has motivated a repeat of experiments in this study at conditions that have been reported previously. 
Another aspect of this investigation is the treatment of facility effects. The conditions such as pressure and temperature behind the reflected shock are ideally constant. However, in the real process both the pressure and temperature behind the reflected shock increase with time due to boundary layer effects inside the shock tube and the non-ideal opening of diaphragms. This leads to pressure and temperature gradients influencing the ignition process. As a result, the measured ignition delay times may be shorter than those assuming ideal conditions. More detailed discussion on these shock tube facility effects can be found in [85]. In general, these effects become stronger with smaller inner diameter tubes and longer measuring times. In Figure 2 the results of shock tubes with inner diameters of $50 \mathrm{~mm}$ [83], $63.5 \mathrm{~mm}$ (this study) and $140 \mathrm{~mm}$ [82] are shown. In [82] an average pressure gradient of $\mathrm{p} / \mathrm{p}_{0}=3 \% / \mathrm{ms}$ is given for the $140 \mathrm{~mm}$ tube. The PCFC tube has an average pressure gradient of $8 \% / \mathrm{ms}$ due to the smaller inner diameter. This pressure gradient has been determined from non-reactive measurements (Figure 3). Pressure gradients of the $50 \mathrm{~mm}$ tube have previously been reported to amount to around $10 \% / \mathrm{ms}$ [85].

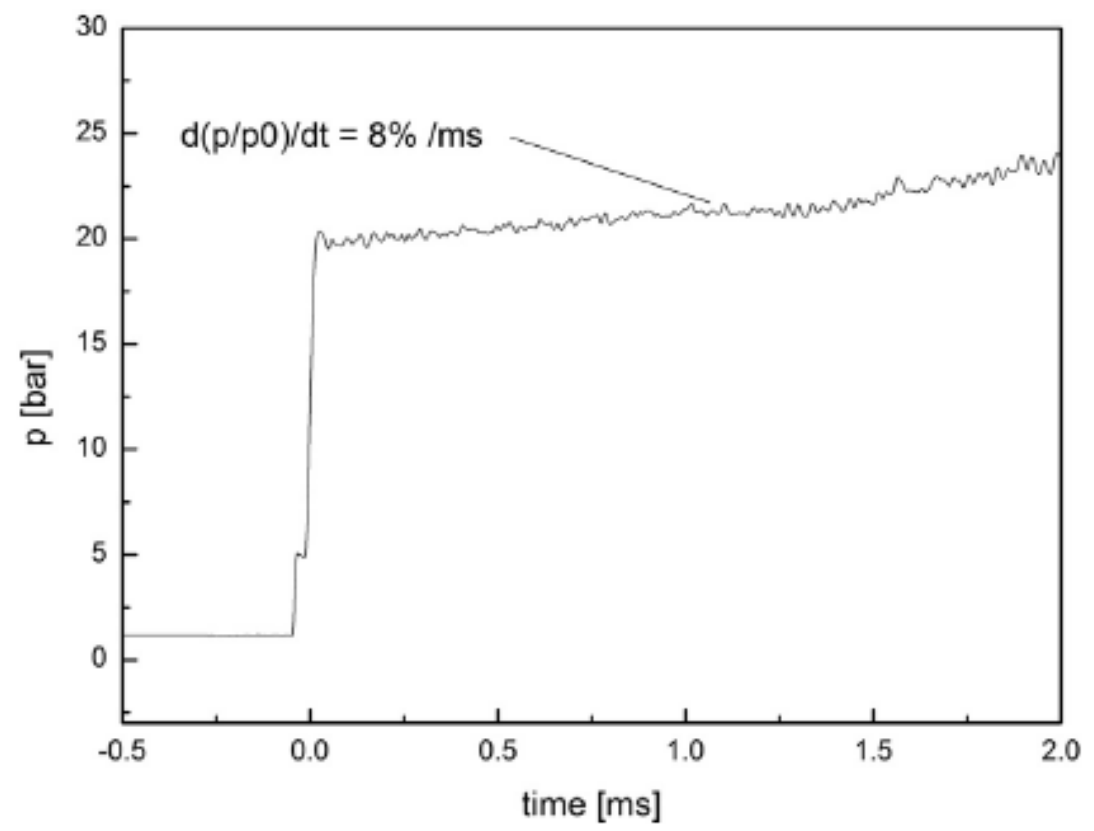

Figure 3: An example non-reactive pressure trace.

At high pressures, where ignition delay times are well below $1 \mathrm{~ms}$, these different pressure gradients hardly have an effect on ignition delay times and in this case the simulations can be performed assuming a truly constant volume reactor. For longer measuring times above $1 \mathrm{~ms}$, facility effects are taken into account by assuming a volume change reflecting the experimentally observed constant increase in pressure as appropriate, depending on the shock tube as discussed above. Comparing the experimental results with the kinetic simulation including a proper treatment of the facility induced increase in pressure and temperature, it becomes obvious that the mechanism is able to predict the measured ignition delay times within $15 \%$, which is within the experimental uncertainty.

It can be seen in Figure 2 that the model predicts well the measured ignition delay times when the facility effect is considered (solid lines). The previous and current results appear inconsistent in ignition delay times at 38 bar, because both the current experiments and simulations were not performed at precisely 38 bar as in [82] (see the experimental data in the Supplementary material). Therefore the inconsistency is caused by the pressure effect. By using the specific experimental temperatures and pressures in our simulations, the model can successfully reproduce both the current and the previous experimental results. It is worth noting that the simulations using varying volume traces obtained from the experimentally measured non-reactive pressure profiles are very similar 
to those assuming an average constant increase in pressure of $8 \% / \mathrm{ms}$, which is consistent with the average pressure gradient of $7-8 \% / \mathrm{ms}$ assumed for the PCFC shock tube. The dashed lines in Figure 2 represent the simulations with the current mechanism using unmodified rate rules, which tend to under-predict ignition delay times over the entire temperature range. This trend is similar to those observed in the kinetic and modeling study of $n$-hexane [54].

As an additional input to the ignition delay times at higher temperature, Figure 4 shows the ignition delay times measured in the high-pressure shock tube at NUIG for $n$-heptane oxidation at $\varphi=1.0$ and 15 bar in the temperature range 1058-1298 K. The agreement between the experimental (points) and modeling results (solid line) are good, which further validates the high temperature $n$-heptane chemistry. The dashed line shows model simulations with unmodified rate rules. The slight difference between the predictions indicates that those modifications have only a minor effect in this temperature regime.

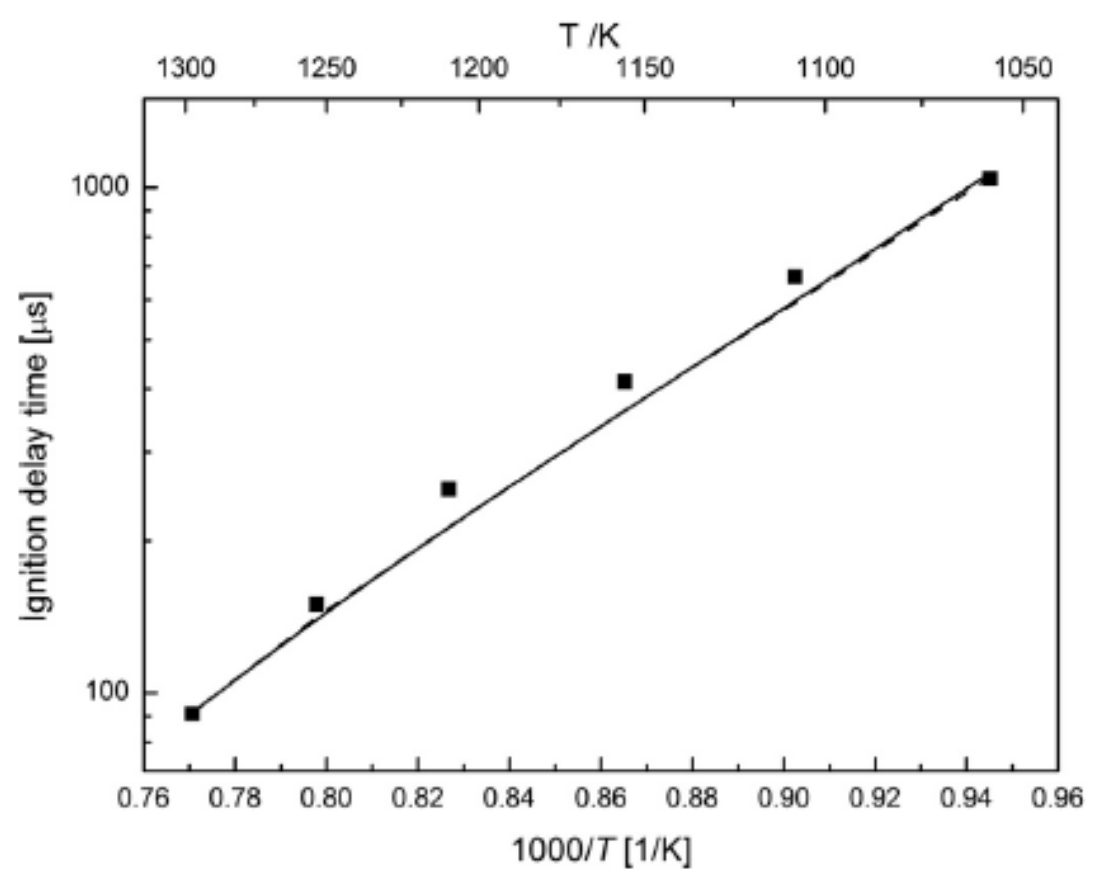

Figure 4: Experimental (symbols) and modeling results (lines) for ignition delay times of stoichiometric $n$-heptane/air mixture at 15 bar. Solid and dashed lines are predictions with and without the modifications in the rate rules, respectively.

The mechanism has also been validated using shock tube ignition delay time data from the literature. Campbell et al. [86] used a shock tube to measure ignition delay times for $n$-heptane oxidation in the temperature range $651-823 \mathrm{~K}$ and at pressures between 6.1 and 7.4 atm at $\varphi=0.75$ in $15 \% \mathrm{O}_{2} / 5 \% \mathrm{CO}_{2} / \mathrm{Ar}$ and in $15 \% \mathrm{O}_{2} / \mathrm{Ar}$ mixtures. Both first-stage (cool flame) and second-stage (total) ignition delay times were measured, providing critically needed targets for further validation of kinetic models. Figure 5 shows the experimental and modeling results for that study [86] which used the LLNL mechanism [42], and the predictions using the current model as well as several other models $[16,30,46]$. It can be seen that the current mechanism generally shows a better performance in predicting both the first and the second stage ignition delay times. 

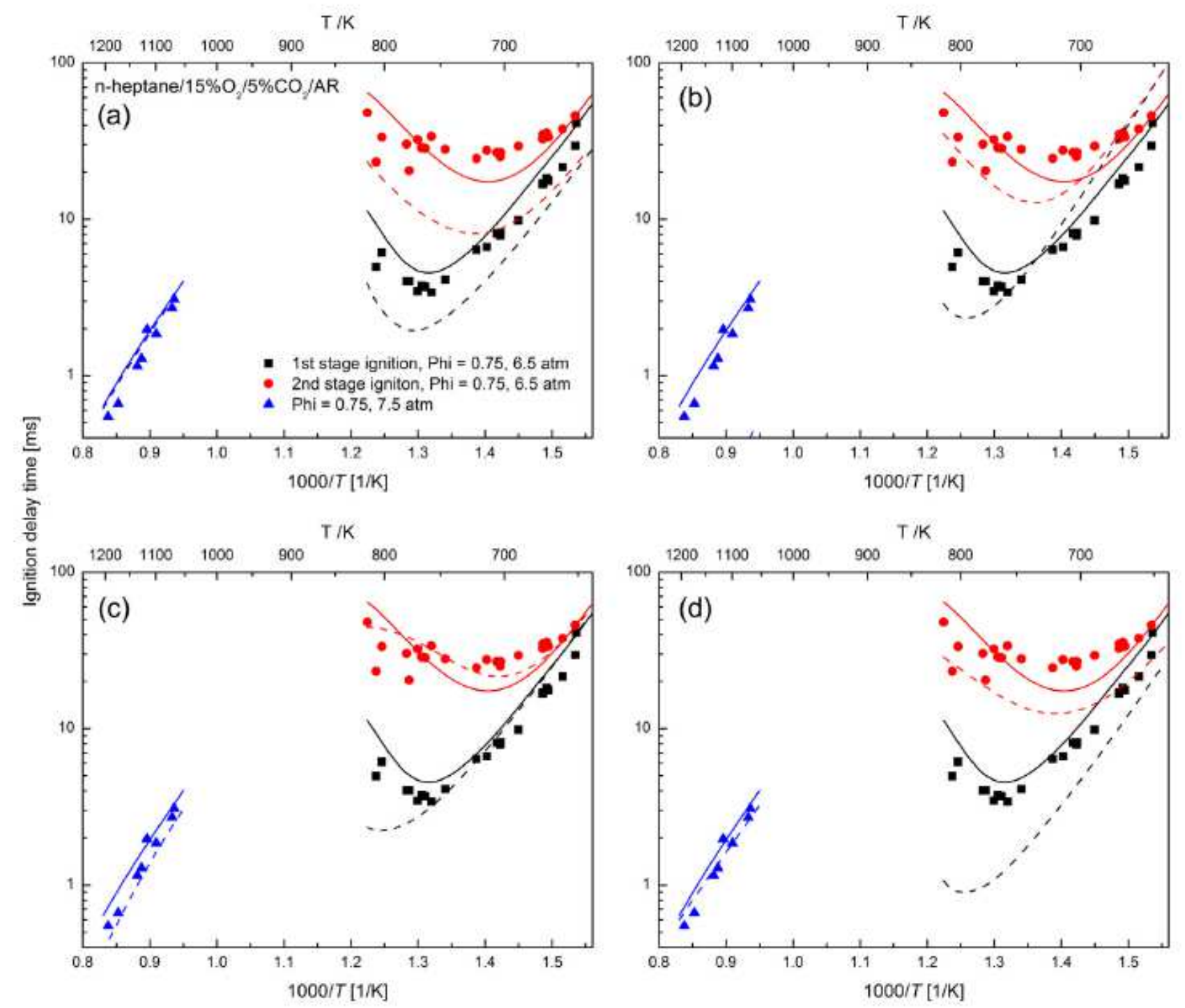

Figure 5: Experimental (symbols) [86] and modeling results (lines) for $n$-heptane $/ 15 \% \mathrm{O}_{2} / 5 \% \mathrm{CO}_{2} / \mathrm{Ar}$ mixture ignition delay times at multiple conditions. Solid lines are predictions using current mechanism and dashed lines are predictions using mechanisms from (a) [42], (b) [16], (c) [30], (d) [46].

Shen et al. [45] measured ignition delay times for several $n$-alkane/air mixtures in a heated shock tube. The experimental results for $n$-heptane, which were measured at $\varphi=0.25,0.5$ and 1.0 at multiple pressures are shown in Figure 6. These results show the varying reactivity of $n$-heptane depending on temperature, pressure and equivalence ratio, which have been well captured by the current model. Here the maximum in excited $\mathrm{OH}$ radical concentration is defined as the ignition delay event, which is consistent with that reported in [45]. Some discrepancies can be seen at conditions such as $\varphi=0.5$ at $13 \mathrm{~atm}$. However, the relevant experimental data is not completely consistent with those under similar conditions shown in Figure 7. Therefore these discrepancies can be partly attributed to the uncertainties of some specific data points from the literature. Ciezki and Adomeit investigated the ignition delay times for $n$-heptane/air mixtures in a high pressure shock tube for equivalence ratios of 0.5 to 3.0, at pressures between 3.2 and 42 bar in the temperature range of 660-1350 K [5]. These experimental data have been the benchmark for validating $n$-heptane oxidation mechanisms $[16,17,30,40,42,44]$ for many years. Figure 7 shows a comparison of the experimental results reported by Ciezki and Adomeit and the predictions using the current mechanism, which indicates that it captures well the trend of the reactivity with the varying equivalence 
ratio, pressure and temperature ranges. The comparison of the predictions using the current mechanism and several other recently published ones [16,30,42,44,46] are shown in Figure 8(a), (b), (c), (d) and (e) respectively.

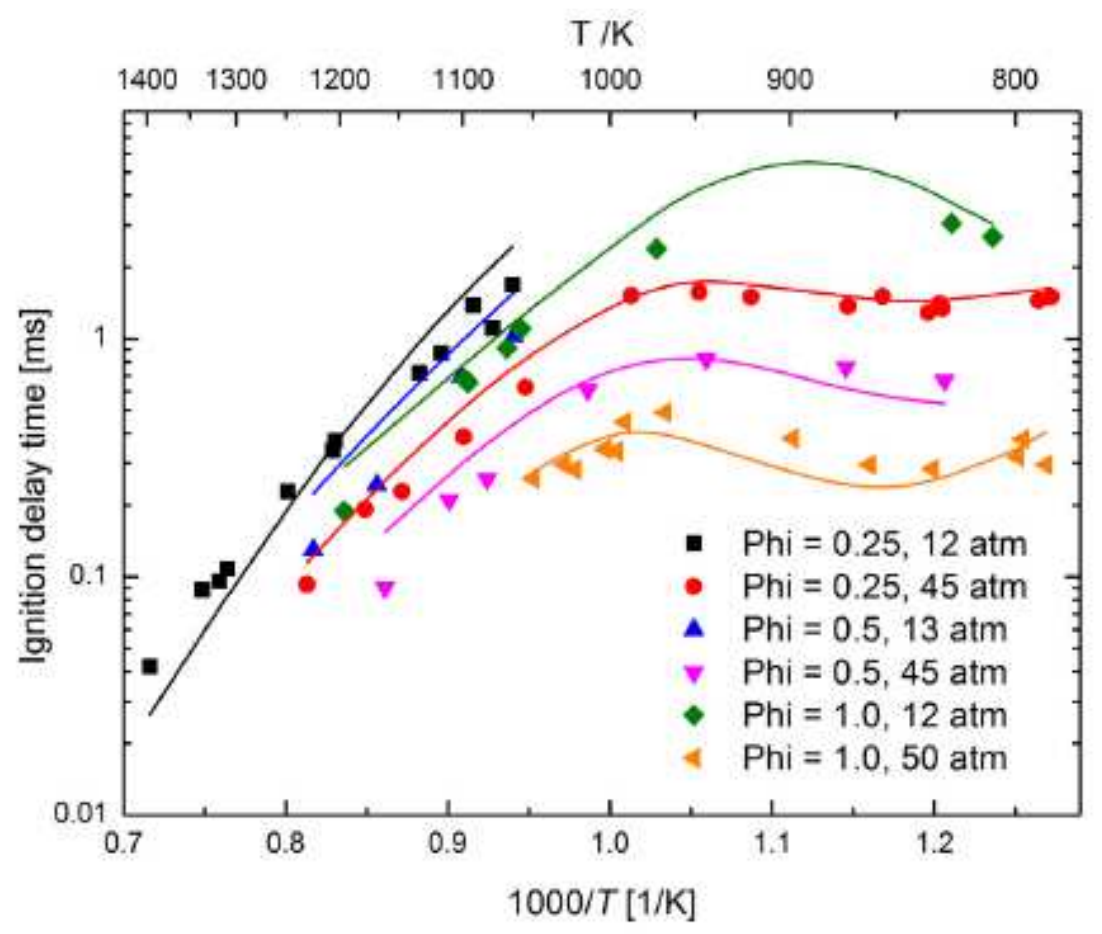

Figure 6: Experimental (symbols) [45] and modeling results (lines) for $n$-heptane/air mixture ignition delay times at multiple conditions.

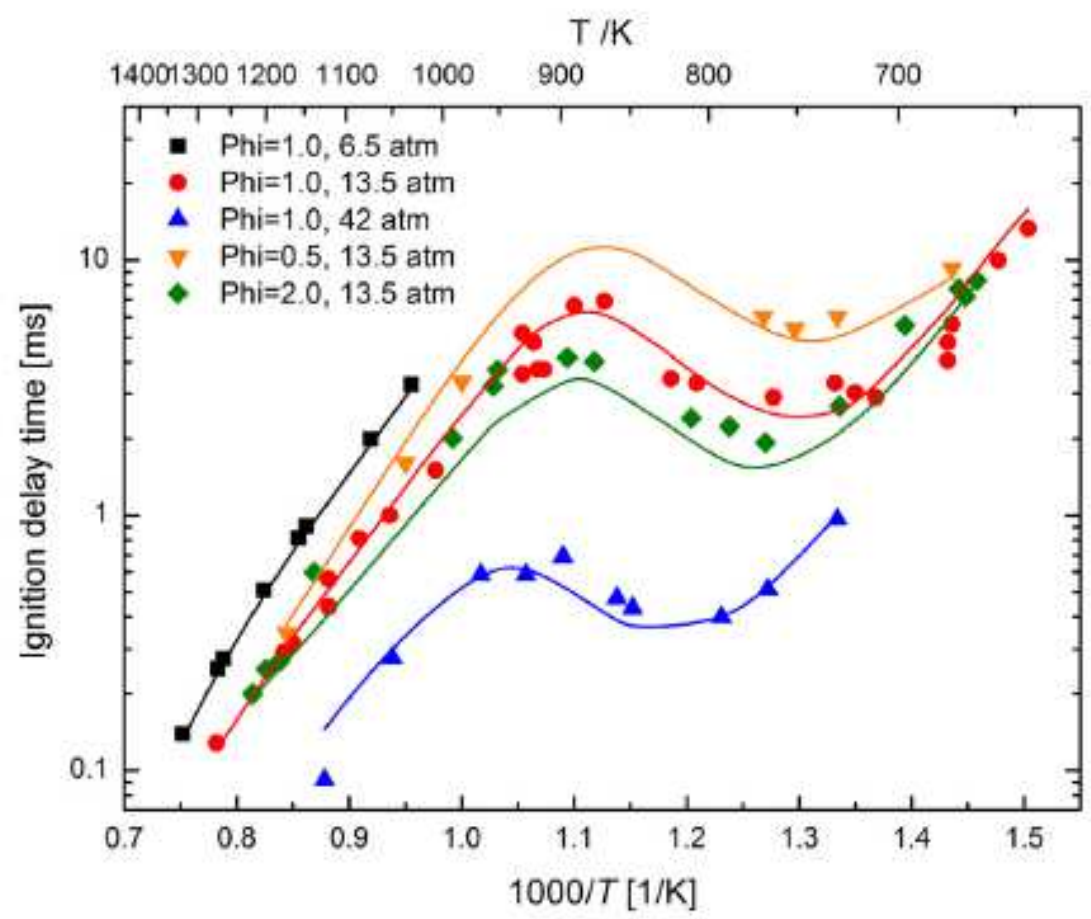

Figure 7: Experimental (symbols) [5] and modeling results (lines) for $n$-heptane/air mixture ignition delay times at multiple conditions. 


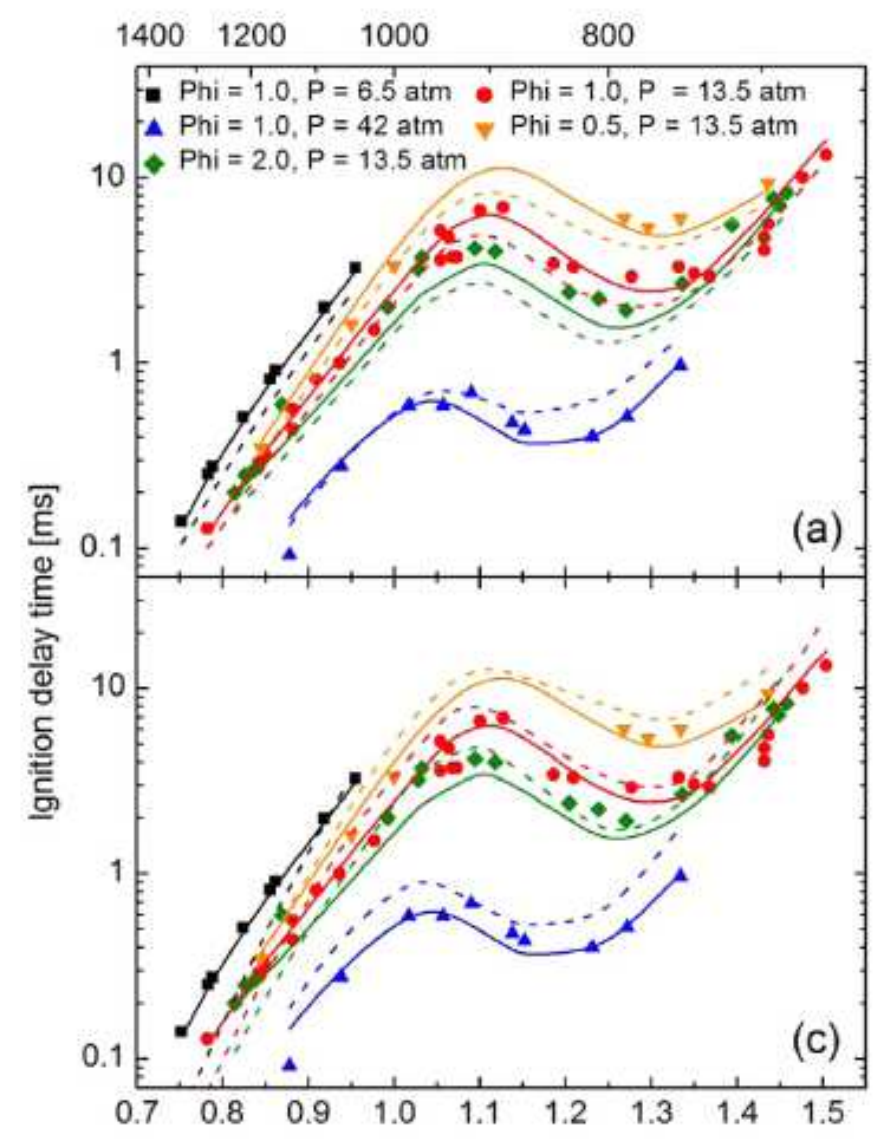

$\mathrm{T} / \mathrm{K}$
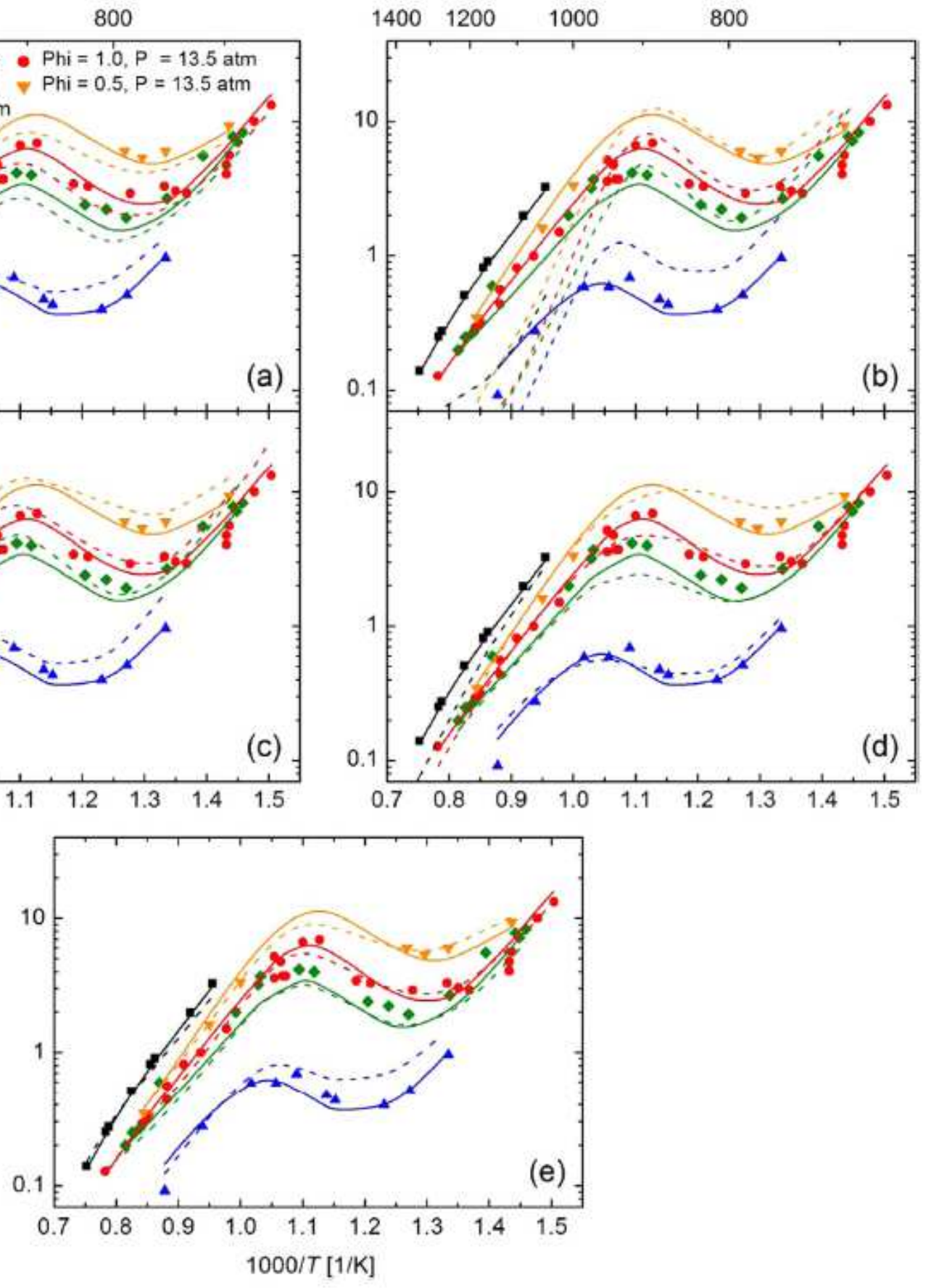

Figure 8: Comparisons of the predicted ignition delay times at multiple conditions using the current mechanism and several other ones proposed recently. Experimental data (symbols) are from [5]. Solid lines are predictions using current mechanism. Dashed lines are predictions using mechanisms from: (a) [42], (b) [16], (c) [44], (d) [30], (e) [46].

A brute force sensitivity analysis was performed using CHEMKIN PRO [84] at $\varphi=1.0, \mathrm{p}=20 \mathrm{bar}, \mathrm{T}=720 \mathrm{~K}$, and at $820 \mathrm{~K}$ and $1000 \mathrm{~K}$ respectively to determine the reactions that are most significant for the ignition process, Figure 9. 


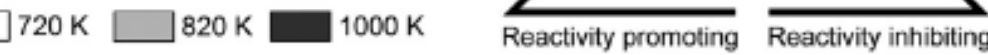

(a) $\quad \mathrm{C} 7 \mathrm{H} 15-4 \mathrm{O} 2<=>\mathrm{C} 7 \mathrm{H} 14-3+\mathrm{HO} 2$ $\mathrm{C} 7 \mathrm{H} 15-3 \mathrm{O} 2 \mathrm{C}=\mathrm{C} 7 \mathrm{H} 14-3+\mathrm{HO} 2$ $\mathrm{C} 7 \mathrm{H} 15-2 \mathrm{O} 2<=>\mathrm{C} 7 \mathrm{H} 14-1+\mathrm{HO} 2$ $\mathrm{C} 7 \mathrm{H} 15-2 \mathrm{O} 2 \Leftrightarrow=\mathrm{C} 7 \mathrm{H} 14-2+\mathrm{HO} 2$ $\mathrm{C} 7 \mathrm{H} 15-3 \mathrm{O} 2 \Leftrightarrow \Rightarrow \mathrm{C} 7 \mathrm{H} 14-2+\mathrm{HO} 2$ $\mathrm{CH} 3 \mathrm{OH}+\mathrm{O} 2<\Leftrightarrow \mathrm{CH} 3 \mathrm{O}+\mathrm{HO} 2$ $\mathrm{OH}+\mathrm{HO} 2<\Leftrightarrow \mathrm{H} 2 \mathrm{O}+\mathrm{O} 2$ $\mathrm{C} 7 \mathrm{H} 13 \mathrm{Q} 25-3 \Leftrightarrow=\mathrm{C} 7 \mathrm{H} 13-2 \mathrm{D} 5 \mathrm{OOH}+\mathrm{HO} 2$ $\mathrm{HO} 2+\mathrm{HO}_{2} \Leftrightarrow=\mathrm{H}_{2} \mathrm{O} 2+\mathrm{O}_{2}$ $\mathrm{C} 7 \mathrm{H} 15-1 \mathrm{O} 2 \Leftrightarrow \mathrm{C} 7 \mathrm{H} 14-1+\mathrm{HO} 2$ C7KET13 $\Leftrightarrow>\mathrm{C} 7 \mathrm{KET} 13 \mathrm{O}+\mathrm{OH}$ $\mathrm{C} 7 \mathrm{H} 14 \mathrm{OOH} 1-3+\mathrm{O} 2<=>\mathrm{C} 7 \mathrm{H} 14 \mathrm{OOH} 1-3 \mathrm{O} 2$ $\mathrm{H} 2 \mathrm{O} 2(+\mathrm{M})<=>\mathrm{OH}+\mathrm{OH}(+\mathrm{M})$ C7KET $35 \Leftrightarrow=\mathrm{C} 7 \mathrm{KET} 35 \mathrm{O}+\mathrm{OH}$ $\mathrm{NC} 7 \mathrm{H} 16+\mathrm{OH} \Leftrightarrow=\mathrm{C} 7 \mathrm{H} 15-4+\mathrm{H} 2 \mathrm{O}$ $\mathrm{C} 7 \mathrm{H} 14 \mathrm{OOH} 4-2+\mathrm{O} 2<=>\mathrm{C} 7 \mathrm{H} 14 \mathrm{OOH} 4-2 \mathrm{O} 2$ C7KET $42 \Leftrightarrow$ C $7 \mathrm{KET} 42 \mathrm{O}+\mathrm{OH}$ $\mathrm{C} 7 \mathrm{H} 14 \mathrm{OOH} 3-5+\mathrm{O} 2<\Leftrightarrow=\mathrm{C} 7 \mathrm{H} 14 \mathrm{OOH} 3-5 \mathrm{O} 2$ C7KET24 $\Leftrightarrow>C 7 \mathrm{KET} 24 \mathrm{O}+\mathrm{OH}$ $\mathrm{C} 7 \mathrm{H} 14 \mathrm{OOH} 2-4+\mathrm{O} 2<=>\mathrm{C} 7 \mathrm{H} 14 \mathrm{OOH} 2-4 \mathrm{O} 2$

(b)

$\mathrm{HO} 2+\mathrm{HO} 2 \Leftrightarrow \Rightarrow \mathrm{H} 2 \mathrm{O} 2+\mathrm{O} 2$ $\mathrm{C} 7 \mathrm{H} 15-2 \mathrm{O} 2<\Rightarrow \mathrm{C} 7 \mathrm{H} 14-1+\mathrm{HO} 2$ $\mathrm{C} 7 \mathrm{H} 15-2 \mathrm{O} 2 \Leftrightarrow=\mathrm{C} 7 \mathrm{H} 14-2+\mathrm{HO} 2$ $\mathrm{C} 7 \mathrm{H} 15-4 \mathrm{O} 2 \Leftrightarrow \mathrm{C} 7 \mathrm{H} 14-3+\mathrm{HO} 2$ $\mathrm{C} 7 \mathrm{H} 15-3 \mathrm{O} 2 \Leftrightarrow \Rightarrow \mathrm{C} 7 \mathrm{H} 14-3+\mathrm{HO} 2$ $\mathrm{C} 7 \mathrm{H} 15-1 \mathrm{O} 2 \Leftrightarrow \mathrm{C} 7 \mathrm{H} 14-1+\mathrm{HO} 2$ $\mathrm{C} 7 \mathrm{H} 15-3 \mathrm{O} 2 \Leftrightarrow \mathrm{C} 7 \mathrm{H} 14-2+\mathrm{HO} 2$ $\mathrm{HO}_{2}+\mathrm{HO}_{2}<\mathrm{-}-\mathrm{H}_{2} \mathrm{O} 2+\mathrm{O}_{2}$ $\mathrm{CH} 2 \mathrm{O}+\mathrm{OH} \Leftrightarrow=>\mathrm{HCO}+\mathrm{H}_{2} \mathrm{O}$ $\mathrm{NC} 3 \mathrm{H}_{7} \mathrm{O} 2<=>\mathrm{C} 3 \mathrm{H} 6+\mathrm{HO}_{2}$ $\mathrm{NC} 7 \mathrm{H} 16+\mathrm{OH}<=>\mathrm{C} 7 \mathrm{H} 15-2+\mathrm{H} 2 \mathrm{O}$ $\mathrm{CH} 3 \mathrm{O} 2+\mathrm{HO} 2<=>\mathrm{CH} 3 \mathrm{O} 2 \mathrm{H}+\mathrm{O} 2$ $\mathrm{CH} 3+\mathrm{HO} 2 \Leftrightarrow=\mathrm{CH} 3 \mathrm{O}+\mathrm{OH}$ $\mathrm{C} 7 \mathrm{H} 14 \mathrm{OOH} 1-3+\mathrm{O} 2<=>\mathrm{C} 7 \mathrm{H} 14 \mathrm{OOH} 1-3 \mathrm{O} 2$ $\mathrm{NC} 7 \mathrm{H} 16+\mathrm{HO} 2 \Leftrightarrow>\mathrm{C} 7 \mathrm{H} 15-2+\mathrm{H} 2 \mathrm{O} 2$ C7 1 14OOH $3-5+\mathrm{O} 2<=>\mathrm{C} 7 \mathrm{H} 14 \mathrm{OOH} 3-5 \mathrm{O} 2$ $\mathrm{C} 7 \mathrm{H} 14 \mathrm{OOH} 4-2+\mathrm{O} 2<=>\mathrm{C} 7 \mathrm{H} 14 \mathrm{OOH} 4-2 \mathrm{O} 2$ $\mathrm{NC} 7 \mathrm{H} 16+\mathrm{OH}<=>\mathrm{C} 7 \mathrm{H} 15-1+\mathrm{H} 2 \mathrm{O}$ $\mathrm{C} 7 \mathrm{H} 14 \mathrm{OOH} 2-4+\mathrm{O} 2<m>\mathrm{C} 7 \mathrm{H} 14 \mathrm{OOH} 2-4 \mathrm{O} 2$ $\mathrm{H} 2 \mathrm{O} 2(+\mathrm{M})<=>\mathrm{OH}+\mathrm{OH}(+\mathrm{M})$

(c) $\quad \mathrm{HO} 2+\mathrm{HO} 2<=>\mathrm{H}_{2} \mathrm{O} 2+\mathrm{O} 2$ $\mathrm{HO} 2+\mathrm{HO} 2<=>\mathrm{H} 2 \mathrm{O} 2+\mathrm{O} 2$ $\mathrm{CH} 3+\mathrm{HO} 2<\Leftrightarrow \mathrm{CH} 4+\mathrm{O} 2$ $\mathrm{NC} 7 \mathrm{H} 16+\mathrm{OH}<=>\mathrm{C} 7 \mathrm{H} 15-3+\mathrm{H} 2 \mathrm{O}$ $\mathrm{C} 4 \mathrm{H} 8-2+\mathrm{O} 2<=>\mathrm{C} 4 \mathrm{H} 71-3+\mathrm{HO} 2$

$\mathrm{C} 7 \mathrm{H} 15-1(+\mathrm{M}) \Leftrightarrow \Rightarrow \mathrm{C} 2 \mathrm{H} 4+\mathrm{C} 5 \mathrm{H} 11-1(+\mathrm{M})$ $\mathrm{PC} 4 \mathrm{H} 9 \mathrm{O} 2 \Leftrightarrow=>\mathrm{C} 4 \mathrm{H} 8 \mathrm{-}-1+\mathrm{HO} 2$ $\mathrm{C} 7 \mathrm{H} 15-2 \mathrm{O} 2<=>\mathrm{C} 7 \mathrm{H} 14-1+\mathrm{HO} 2$ $\mathrm{OH}+\mathrm{HO} 2<=>\mathrm{H} 2 \mathrm{O}+\mathrm{O} 2$

$\mathrm{C} 7 \mathrm{H} 15-1 \mathrm{O} 2<\Rightarrow>\mathrm{C} 7 \mathrm{H} 14-1+\mathrm{HO} 2$ $\mathrm{C} 3 \mathrm{H} 5-\mathrm{A}+\mathrm{HO} 2 \Leftrightarrow=\mathrm{AC} 3 \mathrm{H} 5 \mathrm{OOH}$ $\mathrm{C} 7 \mathrm{H} 15-3+\mathrm{HO} 2 \Leftrightarrow \Rightarrow \mathrm{C} 7 \mathrm{H} 15-3 \mathrm{O}+\mathrm{OH}$ $\mathrm{NC} 7 \mathrm{H} 16<\Rightarrow>\mathrm{PC} 4 \mathrm{H} 9+\mathrm{NC} 3 \mathrm{H} 7$ $\mathrm{C} 3 \mathrm{H} 5-\mathrm{A}+\mathrm{HO} 2<=>\mathrm{C} 3 \mathrm{H} 5 \mathrm{O}+\mathrm{OH}$ $\mathrm{NC} 7 \mathrm{H} 16+\mathrm{HO} 2<=>\mathrm{C} 7 \mathrm{H} 15-1+\mathrm{H} 2 \mathrm{O} 2$ $\mathrm{CH} 3+\mathrm{HO} 2 \Leftrightarrow \Rightarrow \mathrm{CH} 3 \mathrm{O}+\mathrm{OH}$

$\mathrm{NC} 7 \mathrm{H} 16+\mathrm{HO} 2<=>\mathrm{C} 7 \mathrm{H} 15-4+\mathrm{H} 2 \mathrm{O} 2$ $\mathrm{NC} 7 \mathrm{H} 16+\mathrm{HO} 2<m>\mathrm{C} 7 \mathrm{H} 15-2+\mathrm{H} 2 \mathrm{O} 2$ $\mathrm{NC} 7 \mathrm{H} 16+\mathrm{HO}_{2}<=\mathrm{C} 7 \mathrm{H} 15-3+\mathrm{H}_{2} \mathrm{O} 2$ $\mathrm{H} 2 \mathrm{O} 2(+\mathrm{M})<=>\mathrm{OH}+\mathrm{OH}(+\mathrm{M})$
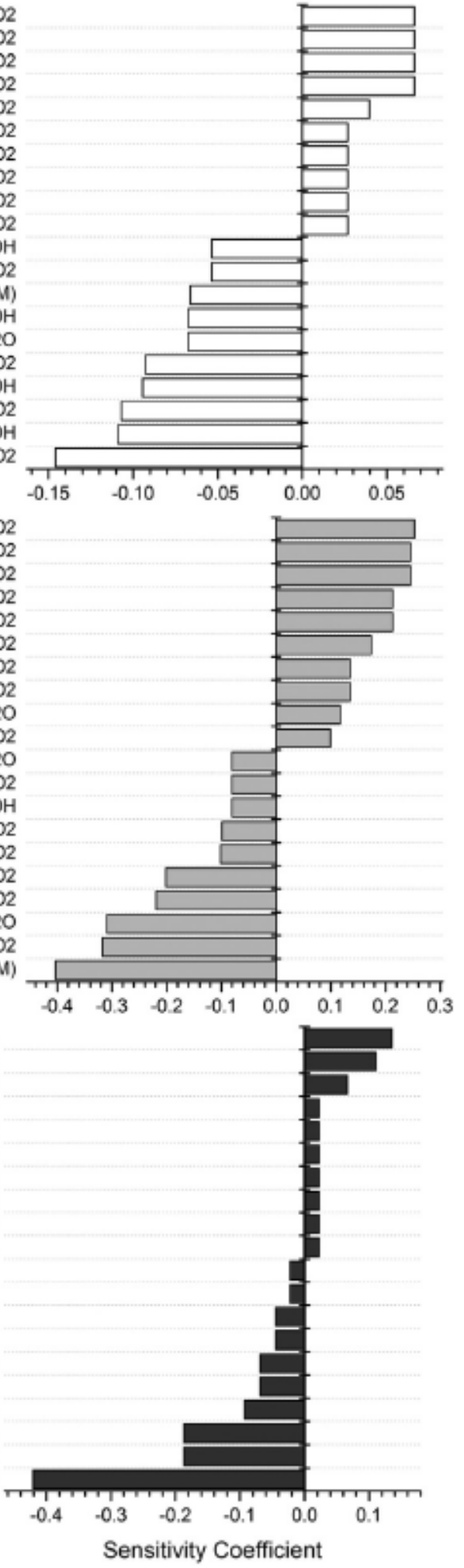

Figure 9: Sensitivity analysis on the ignition delay time of $n$-heptane at $\mathrm{T}=720 \mathrm{~K}, 820 \mathrm{~K}$ and $1000 \mathrm{~K}, \mathrm{P}=20 \mathrm{bar}$. Negative sensitivity coefficients indicate decreases in ignition delay times. 
In the analysis, the rate constants of each reaction were increased and decreased by a factor of two ( $k_{+}$and $\left.k_{-}\right)$, and the simulations were performed using two mechanisms adopting these changes to obtain the ignition delay times $\left(\tau_{+}\right.$and $\left.\tau_{-}\right)$. The sensitivity coefficient $(S)$ is then defined as follows:

$S=\frac{\ln \left(\tau_{+} / \tau_{-}\right)}{\ln \left(k_{+} / k_{-}\right)}=\frac{\ln \left(\tau_{+} / \tau_{-}\right)}{\ln (2 / 0.5)}$

From the definition above, it can be concluded that a reaction with a positive sensitivity coefficient inhibits reactivity while that with a negative sensitivity coefficient promotes reactivity.

At low temperatures, the consumption of the fuel is mainly initiated by $\mathrm{H}$-atom abstraction from the fuel by $\mathrm{OH}$ radicals, followed by propagation via addition to $\mathrm{O}_{2} \rightarrow$ isomerization to $\mathrm{Q}^{\circ} \mathrm{OOH} \rightarrow$ addition to $\mathrm{O}_{2}$, and the branching process via the formation and decomposition of ketohydroperoxides which produce $\mathrm{OH}$ radicals, promoting reactivity. Therefore at low temperatures, the reactivity is dominated by chain branching from the fuel, depicted in Figure 9(a). Hydrogen and other small species chemistry is only of minor importance. The most significant reactions promoting reactivity are those leading to the formation and decomposition of ketohydroperoxides. However, the formation of ketohydroperoxides via the isomerizations of $\dot{\mathrm{O}}_{2} \mathrm{QOOH}$ radicals is not sensitive, because at low temperatures this reaction class dominates the consumption of $\dot{\mathrm{O}}_{2} \mathrm{QOOH}$ radicals, while other consumption pathways such as the beta-scissions of $\mathrm{Q}^{\circ} \mathrm{OOH}$ radicals cannot compete with their addition to molecular oxygen, even when their A factors are reduced by a factor of two. The newly adopted alternative isomerization reactions of $\dot{\mathrm{O}}_{2} \mathrm{QOOH}$ radicals only show minor contributions as discussed in a previous work [54].

$n$-Heptane composes only primary and secondary carbon atoms. H-atom abstraction from fuel by the radical pool mainly occurs at secondary carbon sites because the $\mathrm{C}-\mathrm{H}$ bonds are weaker compared to those on primary carbons. For the same reason, the hydrogen atoms on secondary carbons are favored for the internal $\mathrm{H}$-atom transfer/abstraction process in the isomerization of $\mathrm{RO}_{2}$ to Q $\mathrm{OOH}$ radicals. Meanwhile, the isomerization of $\mathrm{RO}_{2}$ to Q $00 \mathrm{H}$ radicals prefers six-membered ring transition states since they have the lowest ring strain energies. These preferences of relevant reaction classes are also reflected in Fig 9(a). For example, the most sensitive reaction promoting reactivity is the addition of $\dot{\mathrm{C}}_{7} \mathrm{H}_{14} \mathrm{OOH}-4$ radicals to $\mathrm{O}_{2}$. These are produced through the sequence of hydrogen abstraction from a secondary carbon $\rightarrow$ addition to $\mathrm{O}_{2} \rightarrow$ isomerization via a six-membered transition state ring and internal abstraction of a secondary $\mathrm{H}$-atom. The decomposition of the relevant ketohydroperoxide, $\mathrm{C}_{7} \mathrm{KET} 24$, also significantly promotes reactivity. Similarly, the additions of $\dot{\mathrm{C}}_{7} \mathrm{H}_{14} \mathrm{OOH} 3-5$ radicals to $\mathrm{O}_{2}$ also contribute significantly to reactivity, with certain differences caused by the branching ratios of hydrogen abstraction reactions from the fuel. On the other hand, the concerted (olefin $+\mathrm{HO}_{2}$ radical) elimination reactions are the most inhibiting at low temperatures. Although $\mathrm{HO}_{2}$ radicals can abstract hydrogen atoms from the fuel, these reactions are considerably endothermic and contribute little to fuel consumption at low temperatures. In addition, $\mathrm{H}$-atom abstraction from the fuel by $\mathrm{HO}_{2}$ radicals produces $\mathrm{H}_{2} \mathrm{O}_{2}$ which only decomposes easily into $\mathrm{OH}$ radicals at higher temperatures $(\sim 850 \mathrm{~K})$. As has been discussed above, the equilibrium between $\mathrm{RO}_{2}$ and $\mathrm{Q}^{\circ} \mathrm{OOH}$ radicals significantly influences fuel reactivity at low temperatures. This is consistent with Figure 9(a) since the concerted elimination reactions of $\mathrm{RO}_{2}$ play a key role in reducing reactivity, while the addition of $\mathrm{Q}^{\circ} \mathrm{OOH}$ to $\mathrm{O}_{2}$ greatly increases it. The predicted reactivity of $n$-heptane (Figure 2) and $n$-hexane [54] become lower when modified reaction rate rules are used, which can be mainly attributed to the enhanced concerted elimination reactions in the modification [54].

Figure 9(b) shows the results of the sensitivity analysis performed in the NTC region at $820 \mathrm{~K}$. With an increase in temperature, there is an increased competition between chain branching and chain propagation/termination reactions. Under these conditions, the addition of $\mathrm{Q} \cdot \mathrm{OOH}$ radicals to $\mathrm{O}_{2}$ and the concerted elimination reactions of $\mathrm{RO}_{2}$ radicals continue to be important promoting and inhibiting reaction classes, respectively. However, the 
chemistry of small molecules starts to become important. The most important reaction promoting reactivity is the decomposition of $\mathrm{H}_{2} \mathrm{O}_{2}$, while the most inhibiting reaction is the chain termination reaction $\mathrm{HO}_{2}+\mathrm{HO}_{2}=\mathrm{H}_{2} \mathrm{O}_{2}+\mathrm{O}_{2}$. This is because in this reaction two $\mathrm{HO}_{2}$ radicals are consumed to produce just one $\mathrm{H}_{2} \mathrm{O}_{2}$ molecule leading to the formation of two reactive $\dot{\mathrm{O}} \mathrm{H}$ radicals, whereas if one $\mathrm{HO}_{2}$ radical reacts with any stable species two radicals and two $\mathrm{H}_{2} \mathrm{O}_{2}$ molecules will be produced leading to the formation of four reactive OH radicals. Moreover, even though the decomposition of $\mathrm{H}_{2} \mathrm{O}_{2}$ into $\mathrm{OH}$ radicals promotes reactivity, this reaction is endothermic and only becomes significant at higher temperatures. At $820 \mathrm{~K}, \mathrm{HO}_{2}$ radicals can also be converted into more reactive ȮH radicals via reaction with $\mathrm{CH}_{3}$ and $\mathrm{CH}_{3} \dot{\mathrm{O}}_{2}$ radicals, promoting reactivity as shown in Figure $9(\mathrm{~b})$, or inhibit reactivity through the chain-termination reaction producing $\mathrm{H}_{2} \mathrm{O}_{2}$ and $\mathrm{O}_{2}$. However, the temperature can increase to temperatures above $900 \mathrm{~K}$ after the first stage ignition, making the decomposition of $\mathrm{H}_{2} \mathrm{O}_{2}$ much easier and promoting reactivity. The sensitivity coefficients shown in Figure 9(b) reflect the influences of different reactions integrated over the entire ignition process. It indicates that the production and consumption reactions of $\mathrm{HO}_{2}$ radicals play a significant role in the NTC region, and are sensitive to the increase in temperature leading to ignition.

The relatively large sensitivity coefficient of $\mathrm{H}$-atom abstraction from primary carbon atoms indicates the branching ratio of this reaction class is also important in controlling reactivity. As discussed above, $\mathrm{H}$-atom abstraction occurs preferentially from secondary carbon atoms. However, the concerted elimination reaction that inhibits reactivity also favors secondary alkylperoxy radicals, since there are more hydrogen atoms on beta carbons. On the other hand, primary alkylperoxy radicals, $\mathrm{C}_{7} \mathrm{H}_{15}-\dot{\mathrm{O}}_{2}$, only have two hydrogen atoms on the beta carbon leading to the concerted elimination reaction, and therefore there is less competition from this reaction class in the sequent chain branching process. Besides $\mathrm{H}_{2} / \mathrm{O}_{2}$ and $\mathrm{C}_{1}$ chemistry, the reactions of other small molecules also become sensitive. For example, the concerted elimination of $n$-propyl peroxide radical $\left(n \mathrm{C}_{3} \mathrm{H}_{7} \dot{\mathrm{O}}_{2}\right)$ inhibits reactivity. These small molecule radicals are mainly produced from the $\beta$-scission of fuel-derived radicals or from low-temperature products of the chain branching process.

The chemistry of small molecule species is even more important in the high-temperature regime, as shown in Figure 9(c). As the temperature increases, the decomposition of $\mathrm{H}_{2} \mathrm{O}_{2}$ is further enhanced and becomes the dominant reaction promoting reactivity. Correspondingly, $\mathrm{H}$-atom abstraction from fuel by $\mathrm{HO}_{2}$ radicals, which converts $\mathrm{HO}_{2}$ radicals into $\mathrm{H}_{2} \mathrm{O}_{2}$, greatly promotes reactivity. On the other hand, the duplicated chain terminating reactions of $\mathrm{HO}_{2}$ radicals are the most inhibiting reactions, as discussed above. The unimolecular decomposition of the fuel and $\beta$-scission of the fuel-derived radicals show positive or negative sensitivity coefficients depending on the reactivity of the different smaller hydrocarbon species produced. The low-temperature chain branching reactions are not observed to be sensitive in Figure 9(c) due to the high temperature conditions. A series of reactions between small molecule hydrocarbon radicals and $\mathrm{HO}_{2}$ radicals are shown in Figure $9(\mathrm{c})$. In general, those converting $\mathrm{HO}_{2}$ into $\dot{\mathrm{O}}_{\mathrm{H}}$ radicals directly or indirectly promote reactivity, while those converting $\mathrm{HO}_{2}$ into $\mathrm{O}_{2}$ inhibit reactivity.

\subsection{Jet stirred reactor}

The jet-stirred reactor experiments were performed at $1.06 \mathrm{bar}$, at a residence time of $2 \mathrm{~s}$ and at equivalence ratios of $0.25,2.0$ and 4.0 in order to extend the relevant experimental database to very lean $(\varphi=0.25)$ and very rich $(\varphi=$ 4.0) conditions. Detailed compositions of the mixtures are listed in Table 3, with over 40 species being identified. The intermediates include $\mathrm{C}_{1}-\mathrm{C}_{2}$ alcohols, $\mathrm{C}_{1}-\mathrm{C}_{4}$ aldehydes, $\mathrm{C}_{1}-\mathrm{C}_{4}$ alkanes, $\mathrm{C}_{2}-\mathrm{C}_{7}$ alkenes, small molecular dienes and alkynes, $\mathrm{C}_{7}$ cyclic ethers, as well as other oxygenated species such as acids and unsaturated aldehydes, which can be produced from the low-temperature oxidation process. The simulation has been performed using the perfectlystirred reactor module within CHEMKIN PRO [84] employing the transient solver, with an end-time of 20 s. Figures 
10, 11 and 12 present the model versus experimental results at equivalence ratios of $0.25,2.0$ and 4.0, respectively. The experimental data sets are available in the supplementary material.

Table 3: The detailed composition of the reactant mixtures in jet-stirred reactor experiments.

\begin{tabular}{llll}
\hline$\varphi$ & $\begin{array}{l}\text { Inlet concentration }(\%) \\
n \text {-heptane }\end{array}$ & $\mathrm{O}_{2}$ & $\mathrm{He}$ \\
\hline 4.00 & 0.50 & 1.38 & 98.13 \\
2.00 & 0.50 & 2.75 & 96.75 \\
0.25 & 0.50 & 22.00 & 77.50 \\
\hline
\end{tabular}
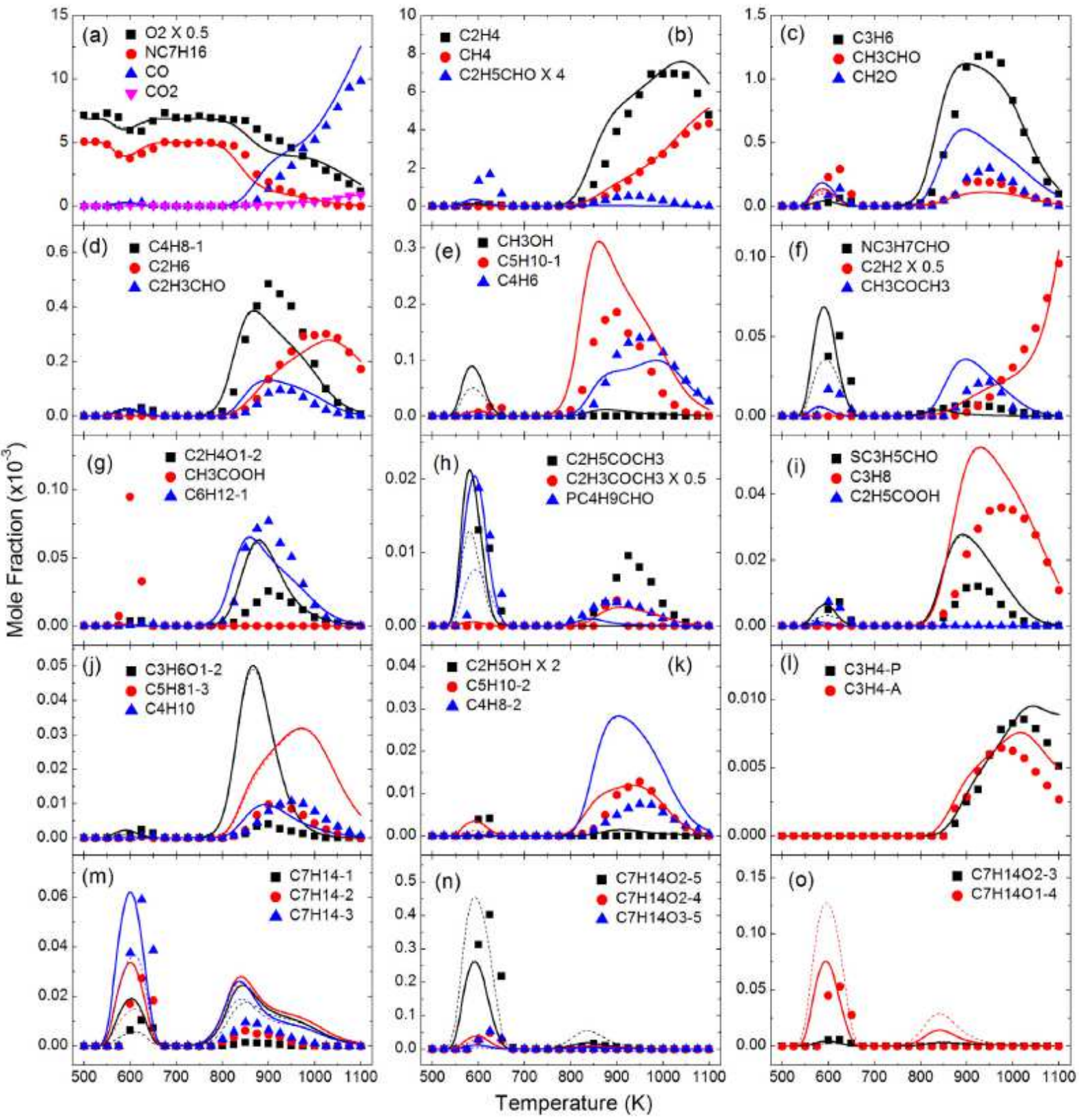

Figure 10: Experimental (symbols) and modeling results (lines) for $n$-heptane oxidation in jet-stirred reactor at 1.06 bar with residence time $=2 \mathrm{~s}, \varphi=4.0,0.5 \%$ fuel diluted by helium. Solid and dashed lines are predictions with and without the modifications in the rate rules, respectively. 

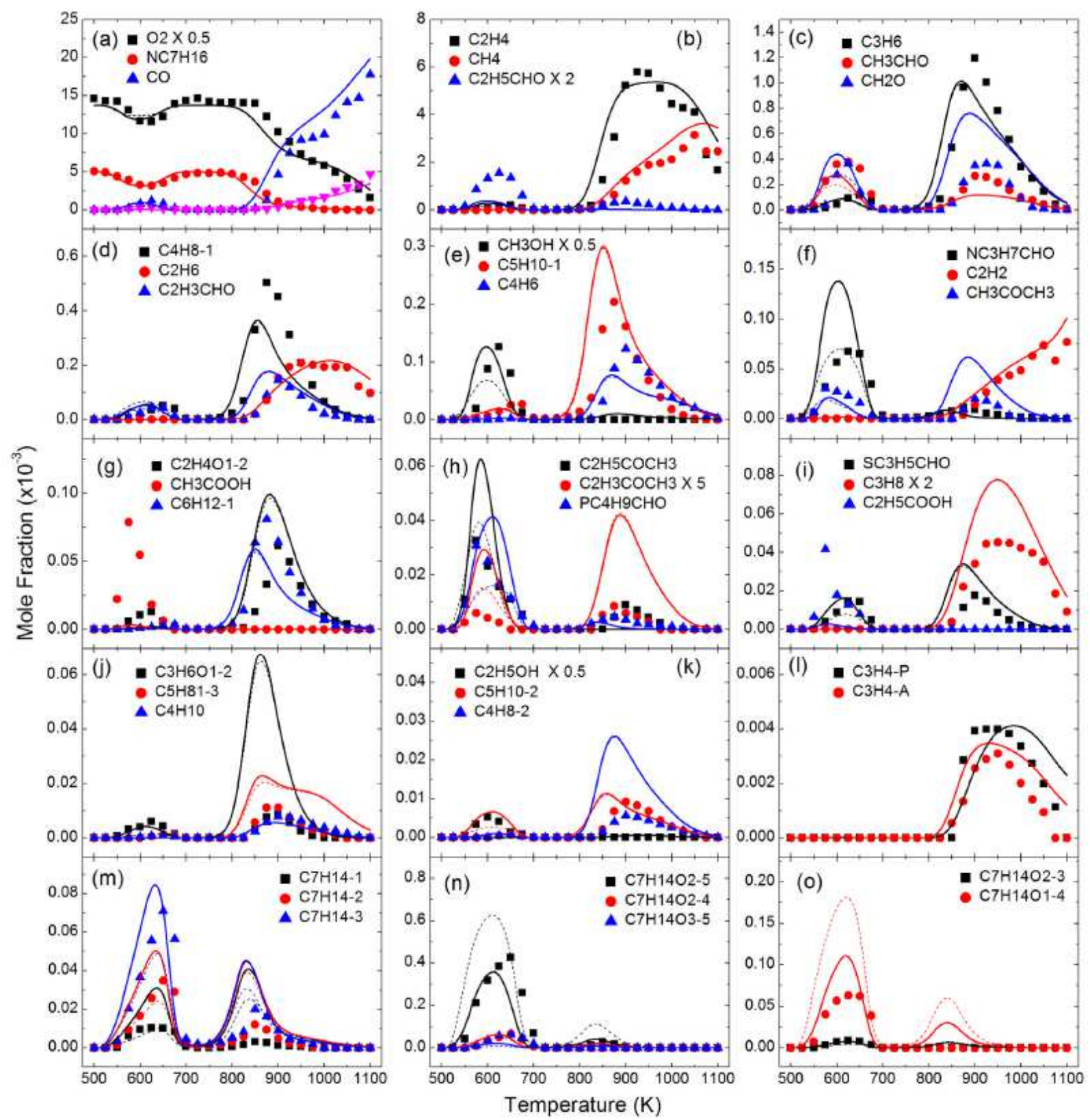

Figure 11: Experimental (symbols) and modeling results (lines) for $n$-heptane oxidation in jet-stirred reactor at 1.06 bar with residence time $=2 \mathrm{~s}, \varphi=2.0,0.5 \%$ fuel diluted by helium. Solid and dashed lines are predictions with and without the modifications in the rate rules, respectively.

The NTC behavior of $n$-heptane under different conditions is reflected in the experimental results. In general, the experimental trends are well captured by the model, except for the under-prediction in reactivity at $\varphi=0.25$ at a temperature of approximately $750 \mathrm{~K}$, indicating that the current mechanism can capture the overall chemical behavior of $n$-heptane under most conditions studied in the present work. Good agreement is observed between the experimental results and the predictions for major intermediates, with the deviations in the peak concentrations being mostly within a factor of two of the experiments. However, the deviations for oxygenated species at low temperatures, such as those shown in Figures 10(j), 11(b) and 11(f), suggest that the consumption pathway of the low-temperature chemistry products can be further refined. In the current mechanism, the Korcek mechanism [87] which produces acids from ketohydroperoxides has also been considered, with the rate constants adopted from 
Pelucchi et al. [44]. However, the effects of adopting this reaction class are very slight, as the concentrations of the acids are under-predicted at all conditions studied in this work, especially for the leanest mixture. This might be due to the fast decomposition of ketohydroperoxides in the current model which requires further investigation of the detailed reaction pathways that consume ketohydroperoxides. The dashed lines present the simulations using the mechanism with unmodified rate rules. It can be see that the new modifications have only a slight effect upon the predicted mole fraction profiles of major species. The dashed lines are overlapping with the solid lines for many cases.
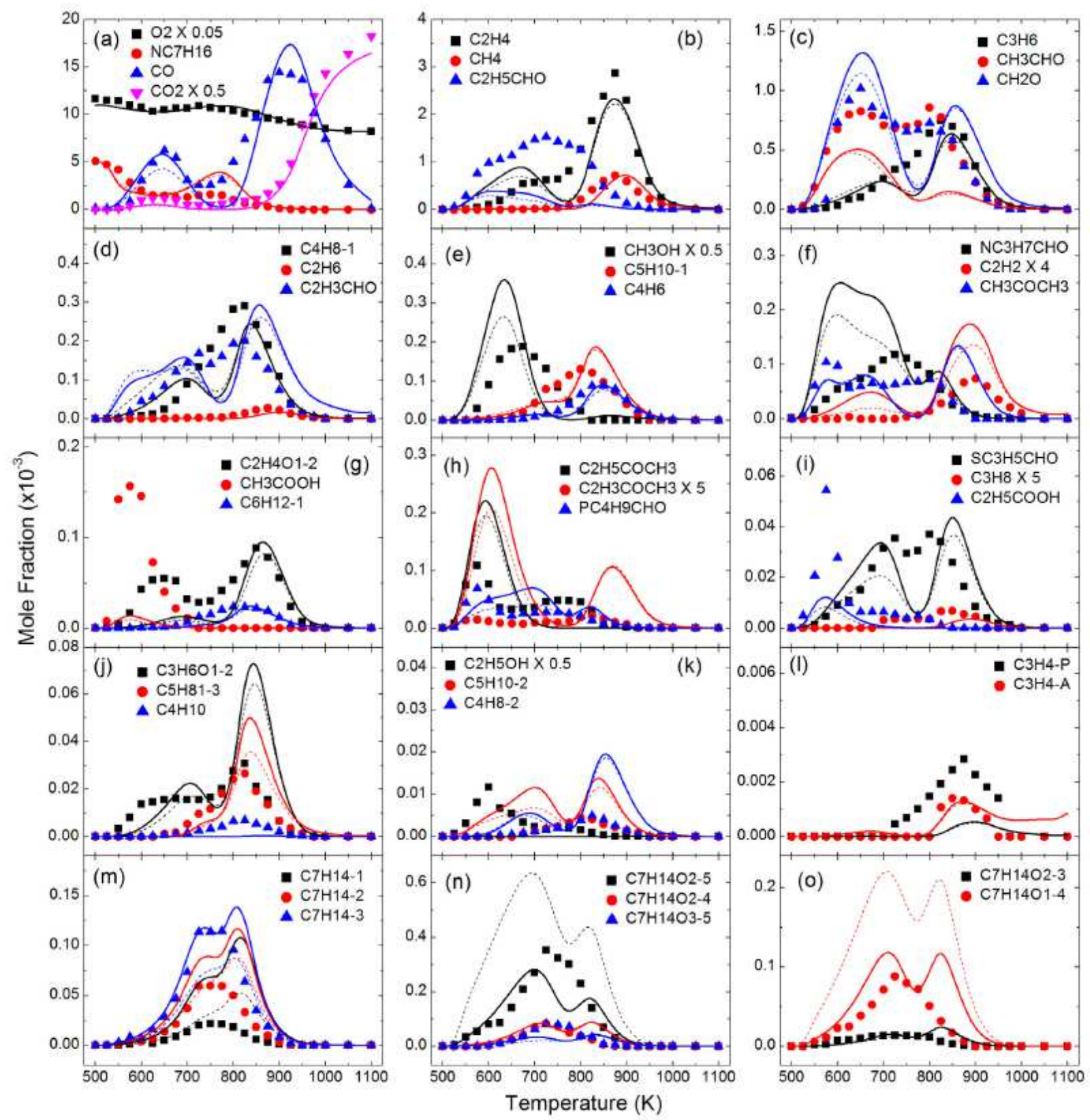

Figure 12: Experimental (symbols) and modeling results (lines) for $n$-heptane oxidation in jet-stirred reactor at 1.06 bar with residence time $=2 \mathrm{~s}, \varphi=0.25,0.5 \%$ fuel diluted by helium. Solid and dashed lines are predictions with and without the modifications in the rate rules, respectively. 
It is worth noting that two important classes of intermediates are reasonably well predicted by the model, that is, heptenes and $\mathrm{C}_{7}$ cyclic ethers. As shown in Figure 10, 11 and $12(\mathrm{~m})$, the heptene isomers are largely produced from the concerted elimination reactions of $\mathrm{RO}_{2}$ radicals, to which ignition delay times are sensitive, showing different effects depending on the temperature range, as discussed earlier. The overall agreement between the model and experimental results of 1-, 2- and 3-heptene are better predicted using the modified rate rules adopted here, yet the branching ratio may need to be further refined. Another possible reason for the deviations, especially those at intermediate temperatures, may be attributable to the consumption pathways of these alkenes. The experimental and simulated mole fraction profiles of five different $C_{7}$ cyclic ethers are shown in Figures 10, 11 and 12(n)-(o). These species are produced from the chain propagating reactions of $\mathrm{Q}^{\circ} \mathrm{OOH}$ radicals forming cyclic ethers and $\mathrm{O}_{\mathrm{H}}$ radicals. Although this reaction class is not seen to be sensitive according to our analysis presented above, its significance for the consumption of $\mathrm{RO}_{2}$ radicals cannot be neglected, as will be shown in the rate of production analysis below. Using the modified rate rules adopted here, in general the predicted mole fraction profiles agree better with the experimental results. Even at $\varphi=0.25$, where the performance of the model is not as good as at the other equivalence ratios, the predicted peak concentration of cyclic ethers match the magnitude of the measured values.

Figures 13 and 14 present the validation of the model against experimental data from previous studies [16,17] in the same jet-stirred reactor. The experimental conditions are similar having a fuel concentration of $0.5 \%$ using helium as the diluent gas. The pressure was 1.06 bar with the residence time of $2 \mathrm{~s}$. The equivalence ratios were 1.0 and 3.0, respectively. The agreement of the predicted mole fraction profiles with the measured ones is good for the major species.
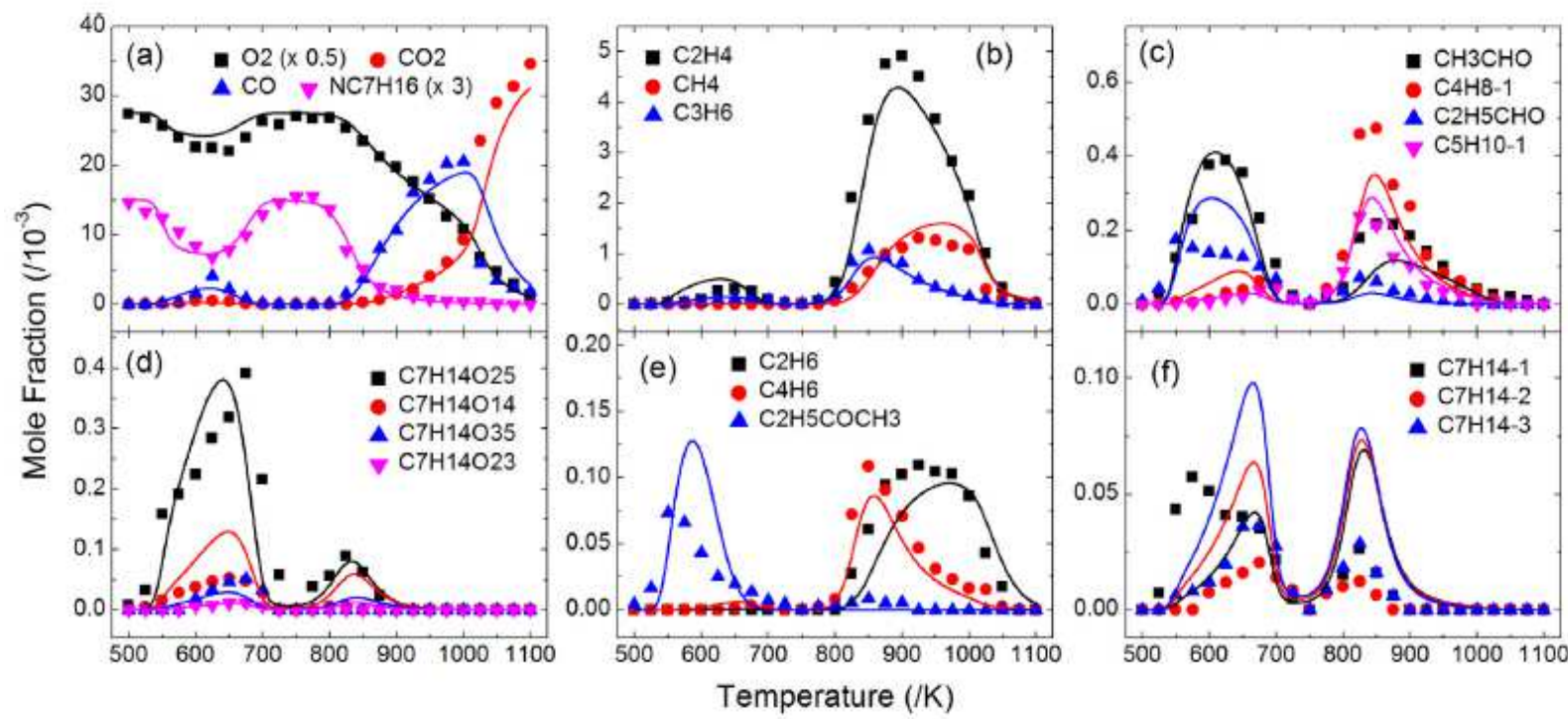

Figure 13: Experimental (symbols) [16] and modeling results (lines) for $n$-heptane oxidation in jet-stirred reactor at 1.06 bar with residence time $=2 \mathrm{~s}, \varphi=1.0,0.5 \%$ fuel diluted by helium.

Figures 13(d) and (f) shows the mole fraction profiles of cyclic ethers and the heptene isomers. The cyclic ethers are well-predicted, while the heptenes are over-predicted within a factor of two. Similar trends are seen in Figure 14(d) for the $\varphi=3.0$ condition, as the concentrations of the two cyclic ethers are well predicted, while the agreement for 1- and 2-heptene shown in Figure 14(f), are better than those at the stoichiometric condition. However, certain deviations are observed at low temperatures for oxygenated species at $\varphi=3.0$, such as acetaldehyde and propanal shown in Figures 14(c) and (e). Figure 15 shows the validations at higher pressures, which uses the experimental data from Dagaut et al. [14]. The model can in general reproduce well the species mole fraction profiles. The 
predicted mole fraction profiles of the heptane isomers agree better with the experimental results as shown in Figure 15(f) compared to those at 1.06 bar, while certain deviations between the experimental and modeling results can be observed for some smaller alkenes such as ethylene and propene as shown in Figures 15(b) and (c). These observations indicate that the consumption pathways for the primary oxidation products of $n$-heptane may need further refinement, possibly by firstly considering their pressure dependence.
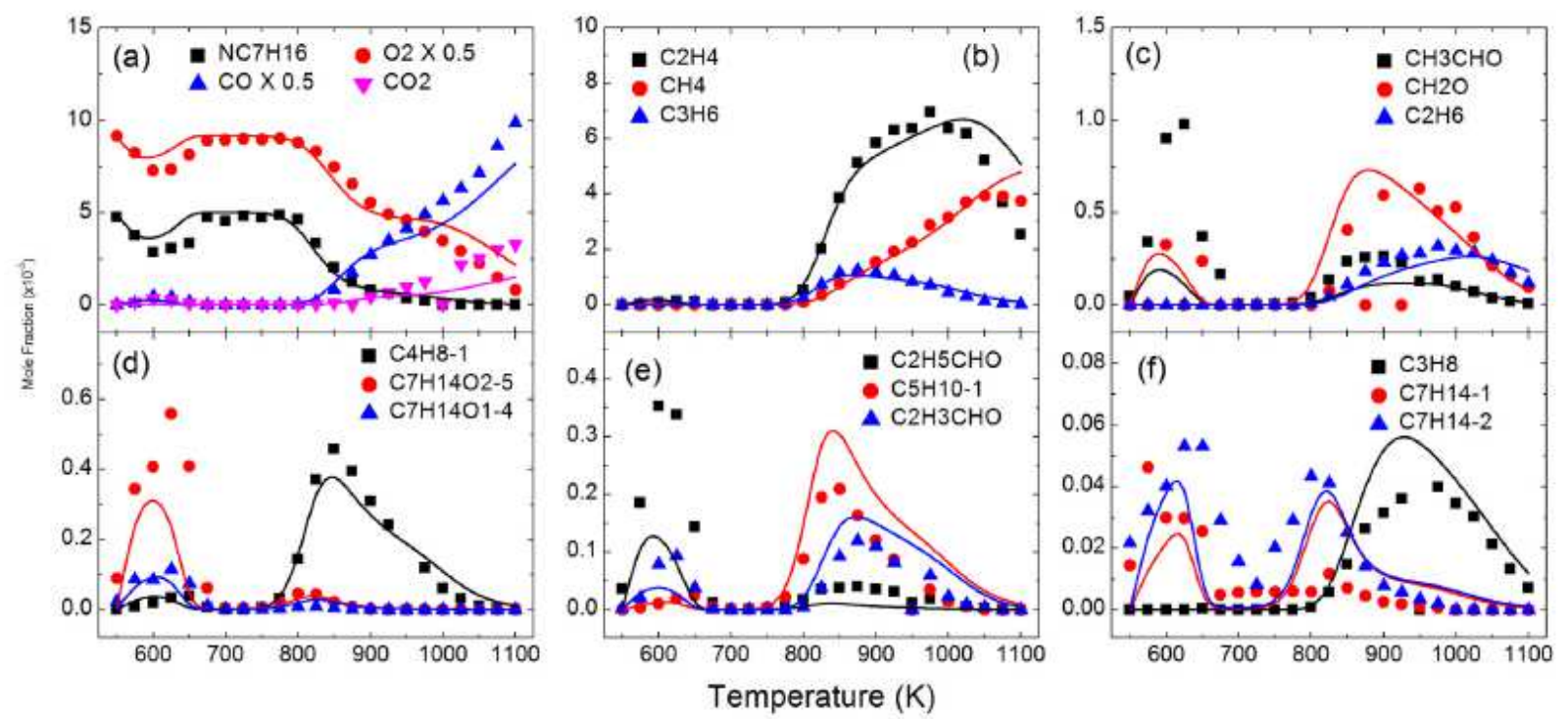

Figure 14: Experimental (symbols) [17] and modeling results (lines) for $n$-heptane oxidation in jet-stirred reactor at 1.06 bar with residence time $=2 \mathrm{~s}, \varphi=3.0,0.5 \%$ fuel diluted by helium.
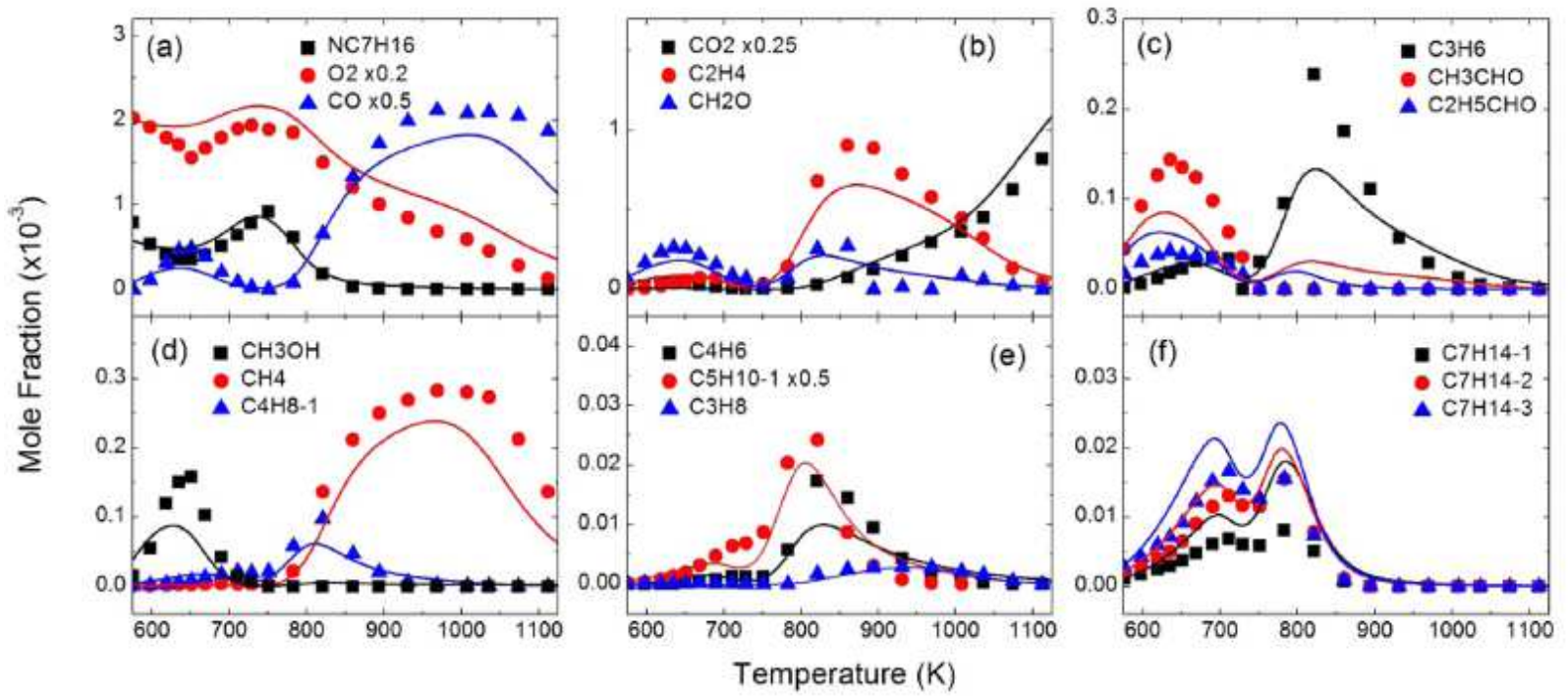

Figure 15: Experimental (symbols) [14] and modeling results (lines) for $n$-heptane oxidation in jet-stirred reactor at 10 bar with residence time $=1 \mathrm{~s}, \varphi=1.0,0.1 \%$ fuel diluted by nitrogen.

Simulations have also been performed using the mechanisms proposed by Mehl et al. [42], Herbinet et al. [16], Pelucchi et al. [44] Seidel et al. [30] and Cai et al. [46] and compared with those of the current mechanism. The experimental data sets are taken from [16]. Comparisons are shown in Figure 16, with each row comparing the simulated results using the current mechanism compared to the target mechanism, which indicates that the current mechanism has an overall better performance. Rate of production analyses have been performed for $n$-heptane 
oxidation in the jet-stirred reactor using helium diluted at $0.5 \%$ fuel, at a residence time of $2 \mathrm{~s}$, at $\varphi=1$, and at $\mathrm{T}=$ 650,850 and $1000 \mathrm{~K}$ in order to reflect the significant reaction pathways over the entire temperature range. Based on the results at the three different temperatures, a reaction pathway diagram has been generated following two principles and is shown in Figure 17.
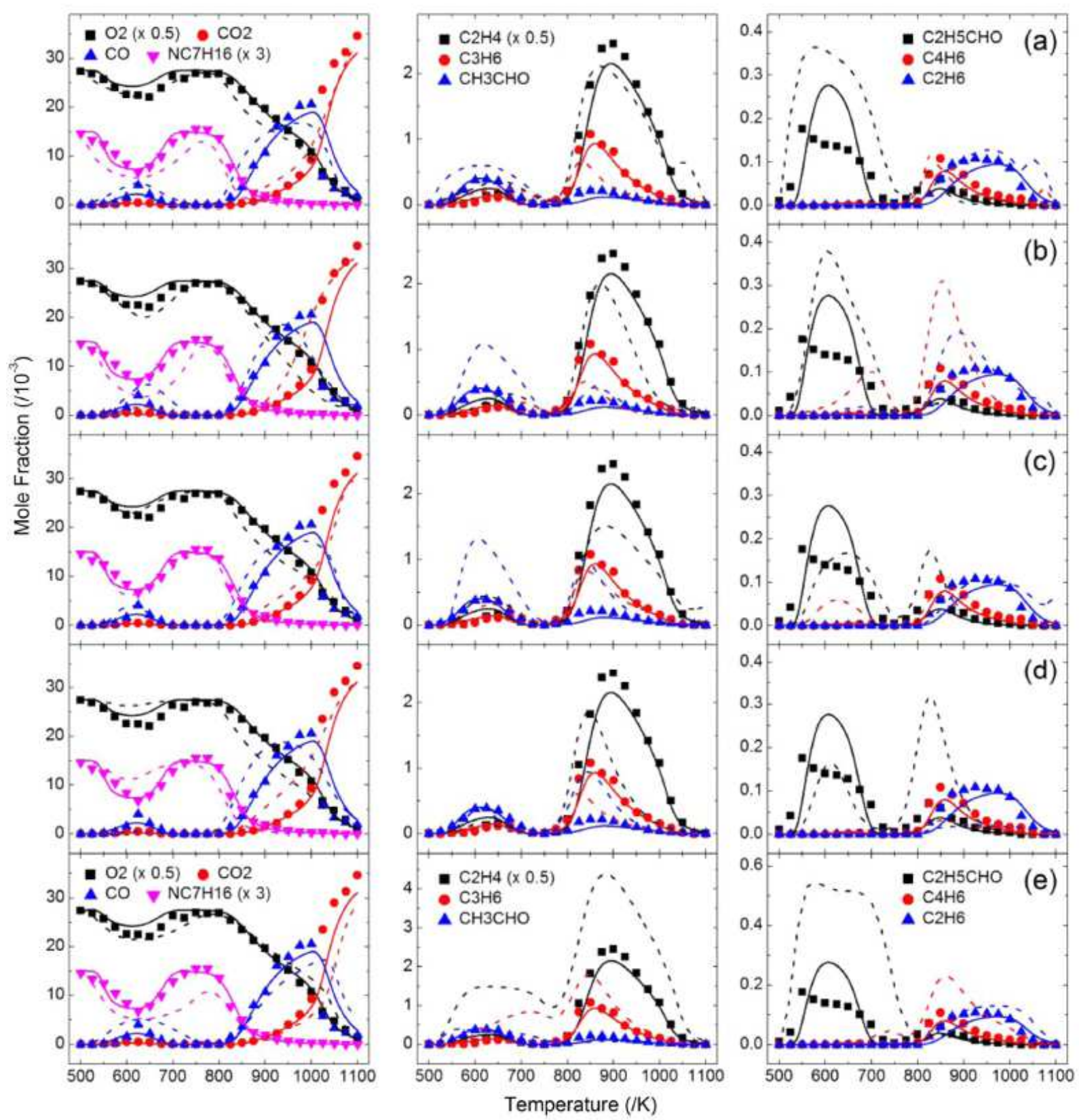

Figure 16: Comparisons of experimental results (symbols) [16] and predictions using the current mechanism and several other ones proposed recently. Solid lines are predictions using current mechanism. Dashed lines are predictions using mechanisms from: Row (a) [42], Row (b) [16], Row (c) [44], Row (d) [30], Row (e) [46].

Considering the neatness of the diagram, the first principle is that, the reaction pathways with contributions of less than $10 \%$ at all three temperatures are not shown. Some of the remaining pathways may have very low contributions at either low or high temperatures due to their dependence on temperature; e.g. the addition of fuel derived radicals to oxygen. Therefore the second principle is that, if a reaction pathway has a contribution of less than $6 \%$, the 
contributions of the sequent reaction pathways of its product are not shown. The arrows denote reaction pathways, with their contributions under different temperatures indicated using different fonts: red italic denotes $\mathrm{T}=650 \mathrm{~K}$, black bold denotes $\mathrm{T}=850 \mathrm{~K}$ and blue underlined denotes $\mathrm{T}=1000 \mathrm{~K}$.

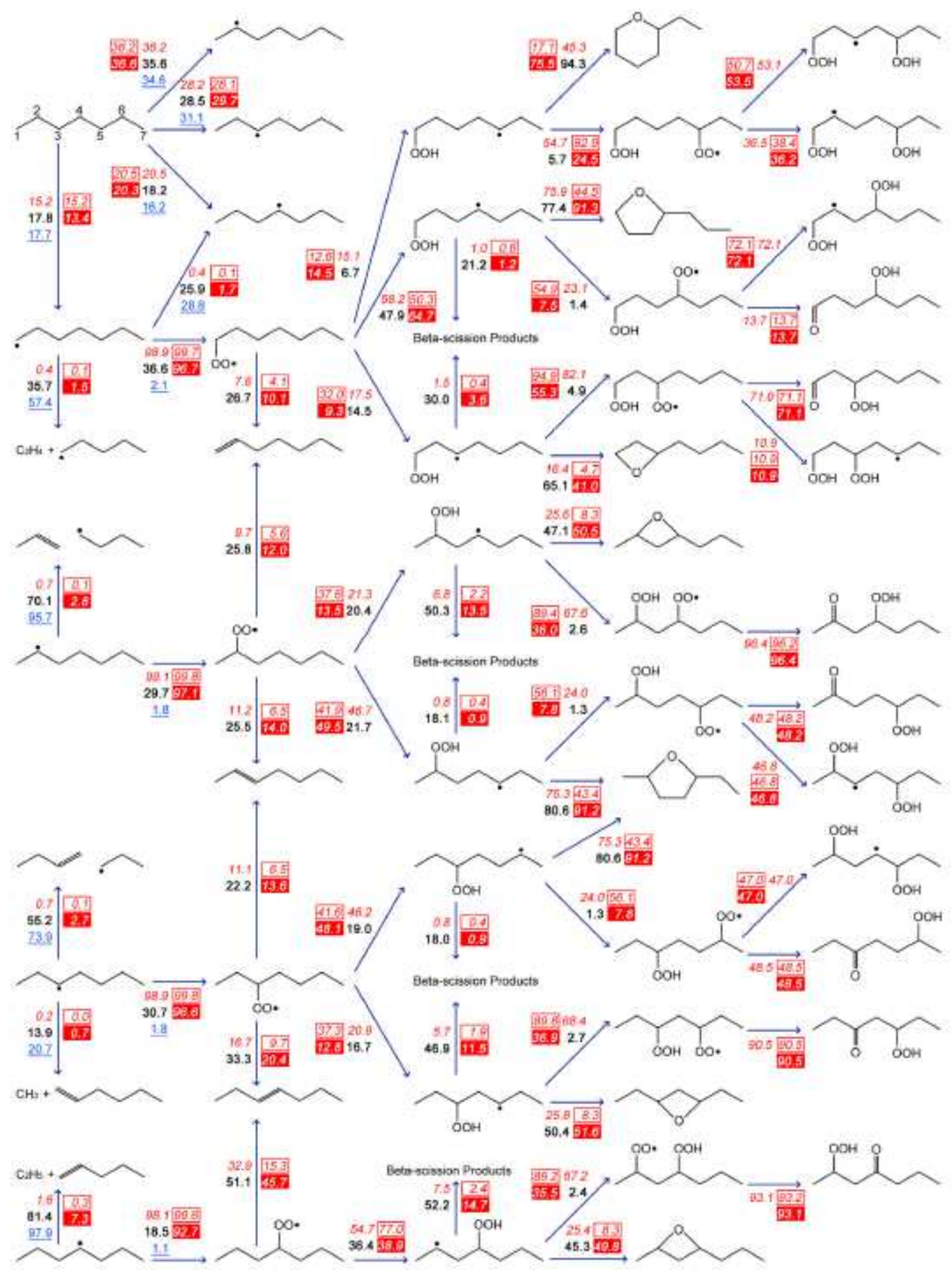

Figure 17: Reaction flux for $n$-hexane oxidation in jet stirred reactor at $P=1.06$ bar with $0.5 \%$ fuel in helium, $\tau=2$ s. The contributions of the reactions are marked. Red italic, black bold and blue underlined numbers are at $\varphi=1.0$, $\mathrm{T}=650 \mathrm{~K}, 850 \mathrm{~K}$ and $1000 \mathrm{~K}$, respectively. Numbers with red frames and red backgrounds are at $\varphi=0.25$ and $\varphi=$ 4.0 at $\mathrm{T}=650 \mathrm{~K}$. (For interpretation of the references to color in this figure legend, the reader is referred to the web version of this article). 
At all three temperatures, fuel consumption occurs mainly via $\mathrm{H}$-atom abstraction by the radical pool, with a slight change in the branching ratios leading to different fuel derived radicals ( $\dot{\mathrm{R}})$. An analysis of the branching ratio for abstraction by different radicals indicates that the contribution of $\mathrm{H}$-atom abstraction by $\mathrm{OH}$ radicals to fuel consumption is $95.8 \%$ at $650 \mathrm{~K}, 78.1 \%$ at $850 \mathrm{~K}$ and $43.5 \%$ at $1000 \mathrm{~K}$, while that by $\mathrm{H}$ atoms is $3.1 \%$ at $650 \mathrm{~K}, 9.1 \%$ at $850 \mathrm{~K}$ and $52.7 \%$ at $1000 \mathrm{~K}$. This reflects the inhibited chain propagating process due to increasing temperature, as well as the enhanced $\beta$-scission of fuel derived radicals which readily produce $\dot{H}$ atoms in the sequent dehydrogenation reactions. This overall trend can also be observed from the change in flux distribution with increasing temperature. Unlike those of $\mathrm{OH}$ radicals and $\dot{\mathrm{H}}$ atoms, the contributions to fuel consumption of $\mathrm{H}$-atom abstraction by $\mathrm{HO}_{2}$ radical is $0.7 \%$ at $650 \mathrm{~K}, 9.1 \%$ at $850 \mathrm{~K}$ and $2.2 \%$ at $1000 \mathrm{~K}$. This trend is consistent with the discussions on sensitivity analysis for ignition delay time in that $\mathrm{H}$-atom abstraction from the fuel by $\mathrm{HO}_{2}$ radicals plays an important role at intermediate temperatures $(\sim 850-1300 \mathrm{~K})$. The production of $\dot{R}$ radicals is depicted in the upper left part of Figure 17, and the consumption is shown in the order of 1-, 2-, 3- and 4-heptyl vertically. In general, the chain propagation and chain branching processes in the consumption of each fuel radical are depicted from left to right in Figure 17; the left edge shows the reaction classes such as the $\beta$-scission and isomerization reactions of alkyl radicals, followed by chain propagation reactions including the addition of alkyl radicals to $\mathrm{O}_{2}$, concerted elimination of $\mathrm{RO}_{2}$ radicals producing an $\mathrm{HO}_{2}$ radical and an olefin, which competes with the isomerization of $\mathrm{RO}_{2}$ into Q $\mathrm{OOH}$ radicals. In the middle part of Figure 17, the multiple consumption channels of Q $\mathrm{Q}^{\circ} \mathrm{OOH}$ are shown, including $\mathrm{Q}^{\cdot} \mathrm{OOH}$ radical addition to $\mathrm{O}_{2}$, the formation of cyclic ethers and also the $\beta$-scission reactions producing smaller molecule products. On the right edge, the chain branching step is reached via the formation of ketohydroperoxide species and bi-hydroperoxy alkyl radicals. The formation and decomposition of the former produce two ÖH radicals in total, while the decomposition of the latter also releases two OH radicals. The further decomposition pathways of these species are not depicted here in order to reduce the size of the figure. Alternative isomerization reactions are more important for $\dot{\mathrm{O}}_{2} \mathrm{QOOH}$ radicals where the hydroperoxy groups are on primary carbon atoms. This is because the $\mathrm{C}-\mathrm{H}$ bonds are stronger and are not favored by the internal $\mathrm{H}$-atom transfer process. Although for $n$-heptane, the alternative isomerization reaction leads to chain branching which can also be reached via the formation of ketohydroperoxides, this additional pathway may be important for branched alkanes when the formation of ketohydroperoxides is not possible [51].

At $650 \mathrm{~K}$, the chain branching process dominates, with the production of ketohydroperoxides and bi-hydroperoxyl alkyl radicals at the right end of Figure 17. The $\beta$-scission pathway of each fuel derived radical can be neglected. The concerted elimination reactions of $\mathrm{RO}_{2}$ have lesser contributions compared to those of the isomerization into $\mathrm{Q}^{\circ} \mathrm{OOH}$ radicals. However, ignition delay time predictions are very sensitive to these concerted elimination reactions where an increase in their rate reduces reactivity, as shown in Figure 9. On the other hand, the flux leading to cyclic ethers is quite high. For each RO2 radical, the 1,4 H-atom transfer channel is favored over the other isomerization pathways, and the sequent formation of five membered ring cyclic ethers dominates the consumption of the corresponding Q $\mathrm{OOH}$ radicals. However, the reactivity of the system is in-sensitive to the formation of cyclic ethers because these chain propagation reactions produce $\dot{\mathrm{OH}}$ radicals which are much more reactive than the $\mathrm{HO}_{2}$ radicals produced from the concerted elimination reactions of $\mathrm{RO}_{2}$ radicals at low temperatures. As the temperature increases to $850 \mathrm{~K}$, the chain propagation pathways become more dominant and there is little flux to chain branching and Q $00 \mathrm{H}$ radical addition to $\mathrm{O}_{2}$. An obvious feature in the reaction pathways is that the concerted elimination reactions largely consume $\mathrm{RO}_{2}$ radicals, especially secondary $\mathrm{RO}_{2}$ radicals since there are more hydrogen atoms on the beta carbons. Meanwhile, the formation of cyclic ethers is also enhanced. As has been discussed previously, the production of 1heptyl radicals promotes reactivity, with this class of reaction showing a relatively large sensitivity coefficient at intermediate temperatures. This may be partly explained by the consumption channels of different fuel radicals shown in Figure 17. While the concerted elimination reaction dominates the consumption of 2-, 3- and 4-heptyl 
radicals, the isomerization reactions contribute about $69 \%$ in total to the consumption of 1-heptyl radicals. Therefore the production of 1-heptyl radicals, compared to the other heptyl radicals, increases the chain branching process, and thus promotes reactivity. At the higher temperature condition of $1000 \mathrm{~K}$, the only important consumption pathways for alkyl radicals are $\beta$-scissions, simultaneously producing smaller hydrocarbon radicals and olefins. Therefore the chemistry of these smaller hydrocarbon species becomes important in controlling the reactivity of the system. The addition of alkyl radicals to molecular oxygen has only a minor contribution to the overall flux of the system.

Rate of production analyses have also been performed at $\varphi=0.25$ and $\varphi=4.0$ at $\mathrm{T}=650 \mathrm{~K}$ to determine the influence of equivalence ratio upon the oxidation of $n$-heptane through the reaction pathways shown in Figure 17. The contributions have been marked with numbers in red frames and numbers with red backgrounds for $\varphi=0.25$ and $\varphi=4.0$ at $\mathrm{T}=650 \mathrm{~K}$, respectively. As shown by the experimental conditions in Table 3, the concentration of the fuel remains constant, while that of oxygen varies with increasing equivalence ratio. As a result, the reactions involving oxygen are enhanced at $\varphi=0.25$ and inhibited at $\varphi=4.0$. This is reflected in Figure 17 in that the additions of $\dot{R}$ and Q ${ }^{\circ} \mathrm{OH}$ radicals to molecular oxygen, especially the latter, have higher contributions at the fuel-lean condition. For example, the addition of $\mathrm{C}_{7} \mathrm{H}_{14} \mathrm{OOH} 4-2$ radicals to oxygen account for $89.2 \%, 67.2 \%$ and $35.5 \%$ to its consumption at $\varphi=0.25,1.0$, and 4.0, respectively, shown at the bottom of Figure 17. For the consumption of Q $00 \mathrm{H}$ radicals, the lower contribution of the addition to $\mathrm{O}_{2}$ with an increase in equivalence ratio leads directly to the higher contribution of cyclic ether formation. Meanwhile, the equilibrium between $\mathrm{RO}_{2}$ and $\mathrm{Q}^{\circ} \mathrm{OOH}$ radicals is also affected. As the consumption of $\mathrm{Q}^{\cdot} \mathrm{OOH}$ radicals is actually inhibited by the lack of $\mathrm{O}_{2}$ at the fuel-rich condition, the isomerization of Q $\mathrm{OOH}$ radicals back to $\mathrm{RO}_{2}$ radicals and the consumption of $\mathrm{RO}_{2}$ radicals via other reaction pathways are promoted. Figure 17 shows that the production of 3-heptene from $\mathrm{C}_{7} \mathrm{H}_{15}-4 \mathrm{O}_{2}$ radical contribute $15.3 \%, 32.9 \%$ and $45.7 \%$ to its consumption at $\varphi=0.25,1.0$, and 4.0, respectively. According to the results and discussions of the sensitivity analysis shown in Figure 9, these changes lead to a lower reactivity at fuel-rich conditions, which is consistent with the fuel consumption values shown in Figure 10, Figure 11 and Figure 12(b). On the other hand, the branching ratios in the production of different fuel derived radicals are very similar at all of the three equivalence ratios. This is because $\mathrm{H}$-atom abstraction from the fuel occurs mainly via OH radicals, with only minor contributions from the other radicals, but varies with equivalence ratio. Similarly, the branching ratios of different consumption channels of $\dot{\mathrm{O}}_{2} \mathrm{QOOH}$ radicals are also highly consistent despite of the varying equivalence ratio, since they are mainly consumed via isomerization and sequent decomposition.

\subsection{Laminar flame speed predictions}

The current mechanism has been validated using the laminar flame speed data reported in [24-26]. The comparisons are shown in Figures 18, 19 and 20. The simulation used the premix code in CHEMKIN PRO [84]. Considering the high temperature condition in the flame, the current mechanism has been reduced by removing most of the reactions involving low-temperature species. This reduced mechanism, or the high temperature version of the current mechanism, is also available as Supplementary material and at the $\mathrm{C}^{3}$ website: http://c3.nuigalway.ie/. 


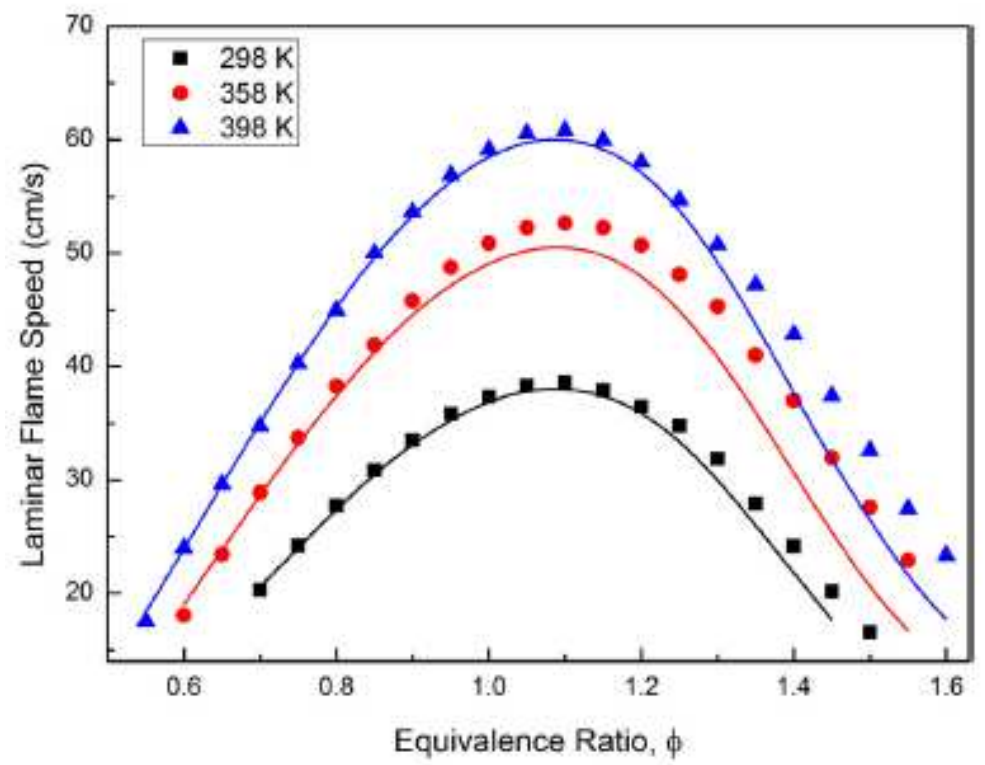

Figure 18: Experimental (symbols) [26] and modeling results (lines) for the laminar flame speed of $n$-heptane in air at $1 \mathrm{~atm}$ and different initial temperatures.

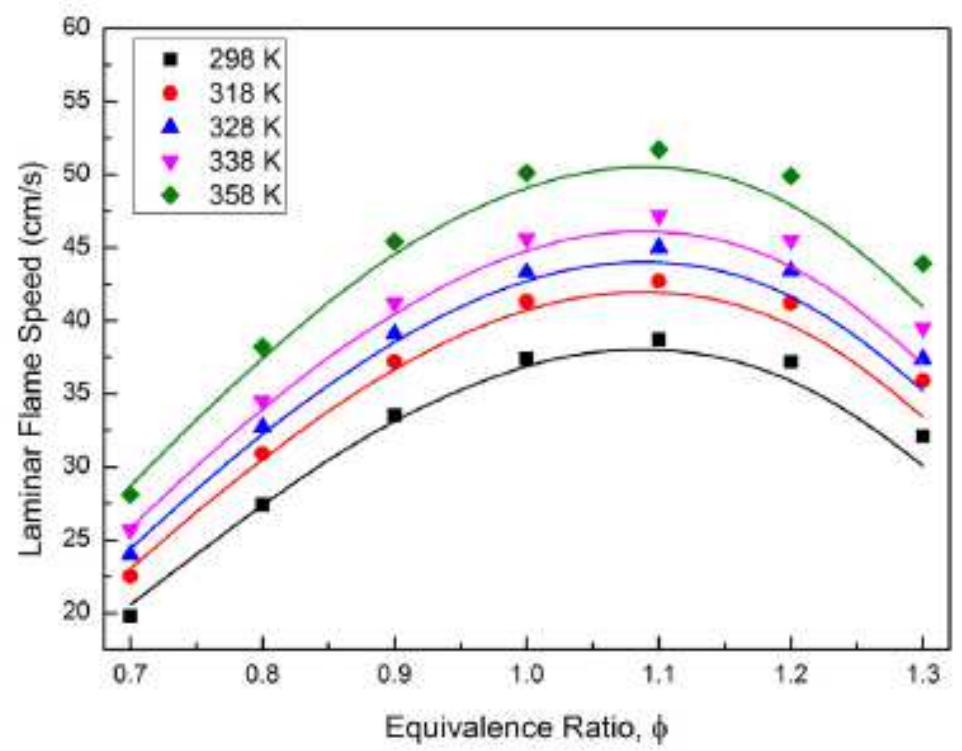

Figure 19: Experimental (symbols) [25] and modeling results (lines) for the laminar flame speed of $n$-heptane in air at $1 \mathrm{~atm}$ and different initial temperatures.

Dirrenberger et al. measured adiabatic laminar burning velocities of $n$-heptane at 1 atm using a flat flame adiabatic burner [26]. The heat flux method was used to determine burning velocities at conditions for which the net heat loss of the flame is zero. Figure 18 shows the experimental data sets reported for $n$-heptane flame speeds, which were measured at $298 \mathrm{~K}, 358 \mathrm{~K}$ and $398 \mathrm{~K}$ [26]. The model predicts well the flame speeds except for the under-prediction at fuel-rich conditions, which is similar to the deviations between the experimental and modeling results presented in the original paper [26]. Sileghem et al. measured the laminar burning velocities of $n$-heptane using the heat flux method for a flat flame adiabatic burner at atmospheric pressure and at multiple initial temperatures from $298 \mathrm{~K}$ to $358 \mathrm{~K}$ [25]. Good agreement can be seen between the experimental data and the simulations using the current model for all data sets at initial temperature from $298 \mathrm{~K}$ to $358 \mathrm{~K}$ (Figure 19). Only slight under-predictions can be seen at 
the initial temperature of $358 \mathrm{~K}$. The deviations are mostly within the reported uncertainty range $( \pm 1.4 \mathrm{~cm} / \mathrm{s}$ for equivalence ratio $=1.3$ and $\pm 1 \mathrm{~cm} / \mathrm{s}$ for the other equivalence ratios).

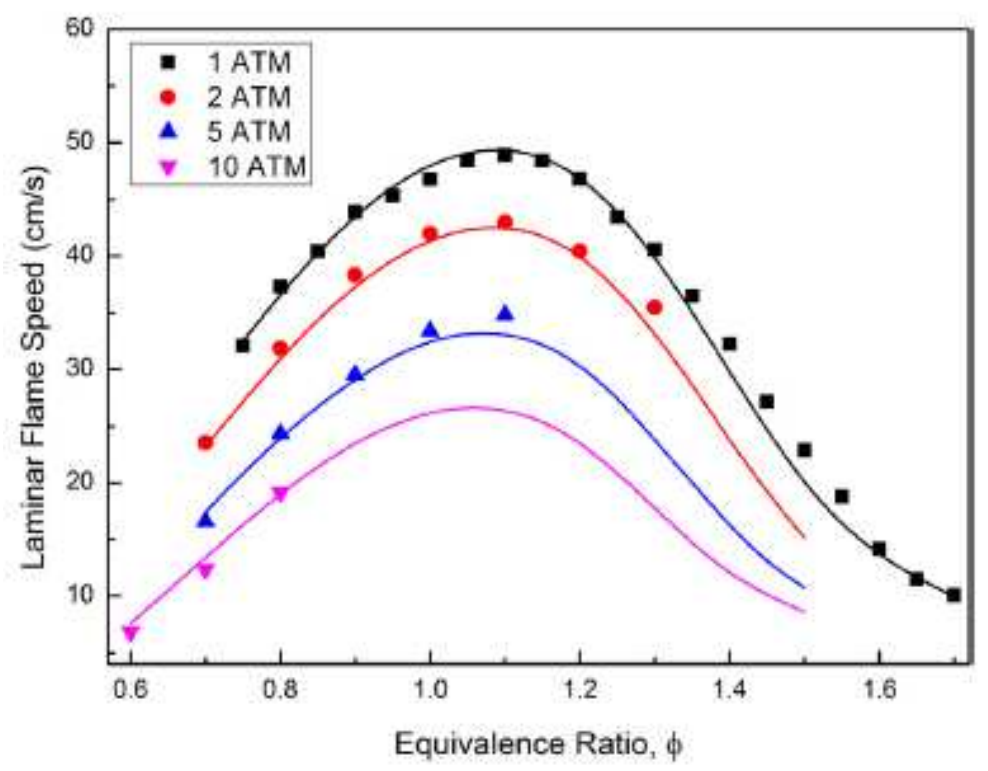

Figure 20: Experimental (symbols) [24] and modeling results (lines) for the laminar flame speed of $n$-heptane in air at initial temperature of $353 \mathrm{~K}$ and different pressures.

The current mechanism has been further validated against flame speed data at elevated pressures. Kelly et al. performed an experimental study on laminar flame speeds and Markstein lengths studies for $\mathrm{C}_{5}-\mathrm{C}_{8} n$-alkane mixtures in air at pressures of up to $10 \mathrm{~atm}$ [24]. Figure 20 shows the measured $n$-heptane flame speeds at an initial temperature of $353 \mathrm{~K}$ and at pressures of 1,2, 5, and $10 \mathrm{~atm}$, respectively. The predicted flame speeds agree well with the experimental results at all pressures, with slight under-predictions at 5 atm which are within the reported uncertainty range of $\pm 2 \mathrm{~cm} / \mathrm{s}$. This indicates that the pressure dependence of the high temperature chemistry is reasonable in the current mechanism.

\section{Conclusions}

In this work, the oxidation of $n$-heptane has been firstly investigated experimentally. A detailed chemical kinetic model has been developed to numerically describe these experimental observations. Good agreement is observed between the model predictions and measured ignition delay times. In general, the model also satisfactorily captures the trend in the mole fraction profiles of most species measured in a jet-stirred reactor over a very wide range of equivalence ratios $(0.25,2.0$ and 4.0). A good performance of the current mechanism is also indicated via further validations and comparisons to several recently published $n$-heptane mechanisms. The reaction rate rules used in this mechanism are consistent with those used for the pentane isomers [51,55] and $n$-hexane [54] sub-mechanisms. Therefore good consistency in kinetic can be expected, which is important regarding simulations for fuel mixtures. The reaction rate rules have been shown to lead to reasonably good predictions and may thus be used in the development of mechanisms of larger alkanes. 


\section{Acknowledgments}

At NUIG, the research leading to these results has received funding from the People Programme (Marie Curie Actions) of the European Union's Seventh Framework Programme FP7/2007-2013/ under REA grant agreement no. 607214. At LRGP, this work was supported by COST Action CM1404. At PCFC, the authors acknowledge the support of the cluster of excellence "Tailor Made Fuels from Biomass" for the work at PCFC, which is funded by the Excellence Initiative by the German federal and state governments to promote science and research at German universities.

\section{Supplementary materials}

- Model files (reactions and kinetic data, thermodynamic properties, transport properties)

- Glossary

- Experimental data

- Uncertainty estimation

\section{References}

[1] 0. Samimi-Abianeh, Development of a new skeletal chemical kinetic mechanism for ethanol reference fuel, J. Eng. Gas Turbines Power, 137 (6) (2015) 061501-1-061501-9

[2] H.J. Curran, W.J. Pitz, C.K. Westbrook, C.V. Callahan, F.L. Dryer, Oxidation of automotive primary reference fuels at elevated pressures, Proc. Combust. Inst., 27 (1998), 379-387

[3] D.J. Vermeer, J.W. Meyer, A.K. Oppenheim, Auto-ignition of hydrocarbons behind reflected shock waves, Combust. Flame, 18 (1972), 327-336

[4] C.M. Coats, A. Williams, Investigation of the ignition and combustion of $n$-heptane-oxygen mixtures, Proc. Combust. Inst., 17 (1979), 611-621

[5] H. Ciezki, G. Adomeit, Shock-tube investigation of self-ignition of $n$-heptane-air mixtures under engine relevant conditions, Combust. Flame, 93 (1993), 421-433

[6] J. Herzler, L. Jerig, P. Roth, Shock tube study of the ignition of lean $n$-heptane/air mixtures at intermediate temperatures and high pressures, Proc. Combust. Inst., 30 (2005), 1147-1153

[7] D.F. Davidson, Z. Hong, G.L. Pilla, A. Farooq, R.D. Cook, R.K. Hanson, Multi-species time-history measurements during $n$-heptane oxidation behind reflected shock waves, Combust. Flame, 157 (2010), 1899-1905

[8] J. Zhang, S. Niu, Y. Zhang, C. Tang, X. Jiang, E. Hu, Z. Huang, Experimental and modeling study of the auto-ignition of $n$-heptane/n-butanol mixtures, Combust. Flame, 160 (2013), 31-39

[9] J.F. Griffiths, K.J. Hughes, M. Schreiber, C. Poppe, A unified approach to the reduced kinetic modeling of alkane combustion, Combust. Flame, 99 (1994), 533-540

[10] R. Minetti, M. Carlier, M. Ribaucour, E. Therssen, L.R. Sochet, A rapid compression machine investigation of oxidation and auto-ignition of $n$-heptane: measurements and modeling, Combust. Flame, 102 (1995), 298-309 
[11] A. Cox, J.F. Griffiths, C. Mohamed, H.J. Curran, W.J. Pitz, C.K. Westbrook, Extents of alkane combustion during rapid compression leading to single-and two-stage ignition, Proc. Combust. Inst., 26 (1996), 2685-2692

[12] E.J. Silke, H.J. Curran, J.M. Simmie, The influence of fuel structure on combustion as demonstrated by the isomers of heptane: a rapid compression machine study, Proc. Combust. Inst., 30 (2005), 2639-2647

[13] A. Chakir, M. Bellimam, J.C. Boettner, M. Cathonnet, Kinetic study of $n$-heptane oxidation, Int. J. Chem. Kinet., 24 (1992), 385-410

[14] P. Dagaut, M. Reuillon, M. Cathonnet, High pressure oxidation of liquid fuels from low to high temperature. 1. $n$ heptane and iso-octane, Combust. Sci. Technol., 95 (1993), 233-260

[15] P. Dagaut, M. Reuillon, M. Cathonnet, Experimental study of the oxidation of n-heptane in a jet stirred reactor from low to high temperature and pressures up to 40 atm, Combust. Flame, 101 (1995), 132-140

[16] O. Herbinet, B. Husson, Z. Serinyel, M. Cord, V. Warth, R. Fournet, P.-A. Glaude, B. Sirjean, F. Battin-Leclerc, Z. Wang, M. Xie, Z. Cheng, F. Qi, Experimental and modeling investigation of the low-temperature oxidation of $n$ heptane, Combust. Flame, 159 (2012), 3455-3471

[17] H.M. Hakka, R.F. Cracknell, A. Pekalski, P.A. Glaude, F. Battin-Leclerc, Experimental and modeling study of ultrarich oxidation of $n$-heptane, Fuel, 144 (2015), 358-368

[18] C.V. Callahan, T.J. Held, F.L. Dryer, R. Minetti, M. Ribaucour, L.R. Sochet, T. Faravelli, P. Gaffuri, E. Rani, Experimental data and kinetic modeling of primary reference fuel mixtures, Proc. Combust. Inst., 26 (1996), 739746

[19] T. Held, A. Marchese, F. Dryer, A semi-empirical reaction mechanism for $n$-heptane oxidation and pyrolysis, Combust. Sci. Technol., 123 (1997), 107-146

[20] D.B. Lenhert, D.L. Miller, N.P. Cernansky, K.G. Owens, The oxidation of a gasoline surrogate in the negative temperature coefficient region, Combust. Flame, 156 (2009), 549-564

[21] P. Veloo, S. Jahangirian, F. Dryer, An experimental and kinetic modeling study of the two stage autoignition kinetic behavior of $\mathrm{C}_{7}, \mathrm{C}_{10}, \mathrm{C}_{12}$, and $\mathrm{C}_{14} n$-alkanes, Proceedings of the Spring Technical Meeting of the Central States Section of the Combustion Institute, Dayton, OH (2012) April 22-24

[22] A.J. Smallbone, W. Liu, C.K. Law, X.Q. You, H. Wang, Experimental and modeling study of laminar flame speed and non-premixed counterflow ignition of $n$-heptane, Proc. Combust. Inst., 32 (2009), 1245-1252

[23] C. Ji, E. Dames, Y.L. Wang, H. Wang, F.N. Egolfopoulos, Propagation and extinction of premixed $\mathrm{C}_{5}-\mathrm{C}_{12} n$-alkane flames, Combust. Flame, 157 (2010), 277-287

[24] A.P. Kelley, A.J. Smallbone, D.L. Zhu, C.K. Law, Laminar flame speeds of $\mathrm{C}_{5}$ to $\mathrm{C}_{8} n$-alkanes at elevated pressures: experimental determination, fuel similarity, and stretch sensitivity, Proc. Combust. Inst., 33 (2011), 963-970 
[25] L. Sileghem, V.A. Alekseev, J. Vancoillie, K.M.V. Geem, E.J.K. Nilsson, S. Verhelst, A.A. Konnov, Laminar burning velocity of gasoline and the gasoline surrogate components iso-octane, $n$-heptane and toluene, Fuel, 112 (2013), 355-365

[26] P. Dirrenberger, P.A. Glaude, R. Bounaceur, H.L. Gall, A.P. d. Cruz, A.A. Konnov, F. Battin-Leclerc, Laminar burning velocity of gasolines with addition of ethanol, Fuel, 115 (2014), 162-169

[27] C. Yao, C. Cheng, S. Liu, Z. Tian, J. Wang, Identification of intermediates in an $n$-heptane/oxygen/argon lowpressure premixed laminar flame using synchrotron radiation, Fuel, 88 (2009), 1752-1757

[28] J. Song, C. Yao, S. Liu, Z. Tian, J. Wang, Experiment study of oxygenates impact on $n$-heptane flames with tunable synchrotron vacuum UV photoionization, Fuel, 88 (2009), 2297-2302

[29] G. Chen, W. Yu, J. Fu, J. Mo, Z. Huang, J. Yang, Z. Wang, H. Jin, F. Qi, Experimental and modeling study of the effects of adding oxygenated fuels to premixed $n$-heptane flames, Combust. Flame, 159 (2012), 2324-2335

[30] L. Seidel, K. Moshammer, X. Wang, T. Zeuch, K. Kohse-Höinghaus, F. Mauss, Comprehensive kinetic modeling and experimental study of a fuel-rich, premixed $n$-heptane flame, Combust. Flame, 162 (2015), 2045-2058

[31] A. Cavaliere, A. Ciajolo, A. D'Anna, R. Mercogliano, R. Ragucci, Autoignition of $n$-heptane and $n$-tetradecane in engine-like conditions, Combust. Flame, 93 (1993), 279-286

[32] D.S. Kim, C.S. Lee, Improved emission characteristics of HCCI engine by various premixed fuels and cooled EGR, Fuel, 85 (2006), 695-704

[33] X.C. Lu, W. Chen, Z. Huang, A fundamental study on the control of the HCCI combustion and emissions by fuel design concept combined with controllable EGR. Part 1. The basic characteristics of HCCI combustion, Fuel, 84 (2005), 1074-1083

[34] X.C. Lu, W. Chen, Z. Huang, A fundamental study on the control of the HCCI combustion and emissions by fuel design concept combined with controllable EGR. Part 2. Effect of operating conditions and EGR on HCCI combustion, Fuel, 84 (2005), 1084-1092

[35] J.P. Szybist, A.L. Boehman, D.C. Haworth, H. Koga, Premixed ignition behavior of alternative diesel fuel-relevant compounds in a motored engine experiment, Combust. Flame, 149 (2007), 112-128

[36] C.K. Westbrook, J. Warnatz, W.J. Pitz, A detailed chemical kinetic reaction mechanism for the oxidation of isooctane and $n$-heptane over an extended temperature range and its application to analysis of engine knock, Proc. Combust. Inst., 22 (1989), 893-901

[37] C. Chevalier, W.J. Pitz, J. Warnatz, C.K. Westbrook, H. Melenk, Hydrocarbon ignition: automatic generation of reaction mechanisms and applications to modeling of engine knock, Proc. Combust. Inst., 24 (1992), 93-101

[38] E. Ranzi, P. Gaffuri, T. Faravelli, P. Dagaut, A wide-range modeling study of $n$-heptane oxidation, Combust. Flame, 103 (1995), 91-106 
[39] G.M. Côme, V. Warth, P.A. Glaude, R. Fournet, F. Battin-Leclerc, G. Scacchi, Computer-aided design of gas-phase oxidation mechanisms - application to the modeling of $n$-heptane and iso-octane oxidation, Proc. Combust. Inst., 26 (1996), 755-762

[40] H.J. Curran, P. Gaffuri, W.J. Pitz, C.K. Westbrook, A comprehensive modeling study of $n$-heptane oxidation, Combust. Flame, 114 (1998), 149-177

[41] C.K. Westbrook, W.J. Pitz, O. Herbinet, H.J. Curran, E.J. Silke, A comprehensive detailed chemical kinetic reaction mechanism for combustion of n-alkane hydrocarbons from $n$-octane to $n$-hexadecane, Combust. Flame, 156 (2009), 181-199

[42] M. Mehl, W.J. Pitz, C.K. Westbrook, H.J. Curran, Kinetic modeling of gasoline surrogate components and mixtures under engine conditions, Proc. Combust. Inst., 33 (2011), 193-200

[43] J. Biet, M.H. Hakka, V. Warth, P.A. Glaude, F. Battin-Leclerc, Experimental and modeling study of the lowtemperature oxidation of large alkanes, Energy Fuels, 22 (2008), 2258-2269

[44] M. Pelucchi, M. Bissoli, C. Cavallotti, A. Cuoci, T. Faravelli, A. Frassoldati, E. Ranzi, A. Stagni, Improved kinetic model of the low-temperature oxidation of $n$-heptane, Energy Fuels, 28 (2014), 7178-7193

[45] H.-P.S. Shen, J. Steinberg, J. Vanderover, M.A. Oehlschlaeger, A shock tube study of the ignition of $n$-heptane, $n$-decane, $n$-dodecane, and $n$-tetradecane at elevated pressures, Energy Fuels, 23 (2009), 2482-2489

[46] L. Cai, H. Pitsch, Optimized chemical mechanism for combustion of gasoline surrogate fuels, Combust. Flame, 162 (2015), 1623-1637

[47] W.K. Metcalfe, S.M. Burke, S.S. Ahmed, H.J. Curran, A hierarchical and comparative kinetic modeling study of $\mathrm{C}_{1}-\mathrm{C}_{2}$ hydrocarbon and oxygenated fuels, Int. J. Chem. Kinet., 45 (2013), 638-675

[48] A. Kéromnès, W.K. Metcalfe, K.A. Heufer, N. Donohoe, A.K. Das, C.-J. Sung, J. Herzler, C. Naumann, P. Griebel, 0. Mathieu, M.C. Krejci, E. Petersen, W.J. Pitz, H.J. Curran, An experimental and detailed chemical kinetic modeling study of hydrogen and syngas mixture oxidation at elevated pressures, Combust. Flame, 160 (2013), 995-1011

[49] S.M. Burke, W.K. Metcalfe, O. Herbinet, F. Battin-Leclerc, F.M. Haas, J. Santner, F.L. Dryer, H.J. Curran, An experimental and modeling study of propene oxidation. Part 1: speciation measurements in jet-stirred and flow reactors, Combust. Flame, 161 (2014), 2765-2784

[50] S.M. Burke, U. Burke, R.M. Donagh, O. Mathieu, I. Osorio, C. Keesee, A. Morones, E.L. Petersen, W. Wang, T.A. DeVerter, M.A. Oehlschlaeger, B. Rhodes, R.K. Hanson, D. Davidson, B.W. Weber, C.-J. Sung, J. Santner, Y. Ju, F.M. Haas, F.L. Dryer, E.N. Volkov, E.J.K. Nilsson, A.A. Konnov, M. Alrefae, F. Khaled, A. Farooq, P. Dirrenberger, P.-A. Glaude, F. Battin-Leclerc, H.J. Curran, An experimental and modeling study of propene oxidation. Part 2: ignition delay time and flame speed measurements combust, Flame, 162 (2015), 296-314

[51] J. Bugler, K.P. Somers, E.J. Silke, H.J. Curran, Revisiting the kinetics and thermodynamics of the low-temperature oxidation pathways of alkanes: a case study of the three pentane isomers, J. Phys. Chem. A, 119 (2015), 7510-7527 
[52] S.M. Burke, J.M. Simmie, H.J. Curran, Critical evaluation of thermochemical properties of $\mathrm{C}_{1}-\mathrm{C}_{4}$ species: updated group-contributions to estimate thermochemical properties, J. Phys. Chem. Ref. Data, 44 (2015), Article 013101

[53] U. Burke, K.P. Somers, P. O'Toole, C.M. Zinner, N. Marquet, G. Bourque, E.L. Petersen, W.K. Metcalfe, Z. Serinyel, H.J. Curran, An ignition delay and kinetic modeling study of methane, dimethyl ether, and their mixtures at high pressures, Combust. Flame, 162 (2015), 315-330

[54] K. Zhang, C. Banyon, C. Togbé, P. Dagaut, J. Bugler, H.J. Curran, An experimental and kinetic modelling study of n-hexane oxidation, Combust. Flame, 162 (2015), 4194-4207

[55] J. Bugler, B. Marks, O. Mathieu, R. Archuleta, A. Camou, C. Grégoire, K.A. Heufer, E.L. Petersen, H.J. Curran, An ignition delay time and chemical kinetic modelling study of the pentane isomers combust, Flame, 163 (2016), 136156

[56] U. Burke, W.K. Metcalfe, S.M. Burke, K.A. Heufer, P. Dagaut, H.J. Curran, A detailed chemical kinetic modeling, ignition delay time and jet-stirred reactor study of methanol oxidation, Combust. Flame, 165 (2016), 125-136

[57] Y. Li, C.W. Zhou, K.P. Somers, K. Zhang, H.J. Curran, The oxidation of 2-butene: a high pressure ignition delay, kinetic modeling study and reactivity comparison with isobutene and 1-butene, Proc. Combust. Inst. (2016)

[58] C.-W. Zhou, Y. Li, E. O'Connor, K.P. Somers, S. Thion, C. Keesee, O. Mathieu, E.L. Petersen, T.A. DeVerter, M.A. Oehlschlaeger, G. Kukkadapu, C.-J. Sung, M. Alrefae, F. Khaled, A. Farooq, P. Dirrenberger, P.-A. Glaude, F. BattinLeclerc, J. Santner, Y. Ju, T. Held, F.M. Haas, F.L. Dryer, H.J. Curran, A comprehensive experimental and modeling study of isobutene oxidation, Combust. Flame, 167 (2016), 353-379

[59] Shock and detonation toolbox, http://shepherd.caltech.edu/EDL/public/cantera/html/SD_Toolbox/, accessed: 2015-11-25

[60] D.G. Goodwin, H.K. Moat, R.L. Speth, Cantera: an object-oriented software toolkit for chemical kinetics, thermodynamics, and transport processes, http://www.cantera.org, version 2.2.0 (2015)

[61] H. Nakamura, D. Darcy, M. Mehl, C.J. Tobin, W.K. Metcalfe, W.J. Pitz, C.K. Westbrook, H.J. Curran, An experimental and modeling study of shock tube and rapid compression machine ignition of $n$-butylbenzene/air mixtures, Combust. Flame, 161 (2014), 49-64

[62] D. Matras, J. Villermaux, Un réacteur continu parfaitement agité par jets gazeux pour l'étude cinétique de réactions chimiques rapides, Chem. Eng. Sci., 28 (1973), 129-137

[63] 0. Herbinet, F. Battin-Leclerc, Progress in understanding low-temperature organic compound oxidation using a jet-stirred reactor, Int. J. Chem. Kinet., 46 (2014), 619-639

[64] A. Andreatch, R. Feinland, Continuous trace hydrocarbon analysis by flame ionization, Anal. Chem., 32 (1960), 1021-1024

[65] W. Dietz, Response factors for gas chromatographic analyses, J. Gas Chromatogr., 5 (1967), 68-71 
[66] "NIST Standard Reference Database 1A", The National Institute of Standards and Technology, June 19, 2014, http://www.nist.gov/srd/nist1a.cfm.

[67] A. Rodriguez, O. Herbinet, Z. Wang, F. Qi, C. Fittschen, P. Westmoreland, F. Battin-Leclerc, Measuring hydroperoxide chain-branching agents during $n$-pentane low-temperature oxidation, Proceedings of the Combustion Institute36 (2016)

[68] S. Sharma, S. Raman, W.H. Green, Intramolecular hydrogen migration in alkylperoxy and hydroperoxyalkylperoxy radicals: accurate treatment of hindered rotors, J. Phys. Chem. A, 114 (2010), 5689-5701

[69] A. Miyoshi, Molecular size dependent falloff rate constants for the recombination reactions of alkyl radicals with $\mathrm{O}_{2}$ and implications for simplified kinetics of alkylperoxy radicals, Int. J. Chem. Kinet., 44 (2012), 59-74

[70] C.F. Goldsmith, W.H. Green, S.J. Klippenstein, Role of $\mathrm{O}_{2}+$ QOOH in low-temperature ignition of propane. 1. Temperature and pressure dependent rate coefficients, J. Phys. Chem. A, 116 (2012), 3325-3346

[71] S.M. Villano, L.K. Huynh, H.-H. Carstensen, A.M. Dean, High-pressure rate rules for alkyl $+\mathrm{O}_{2}$ reactions. 1 . The dissociation, concerted elimination, and isomerization channels of the alkyl peroxy radical, J. Phys. Chem. A, 115 (2011), 13425-13442

[72] S.M. Villano, L.K. Huynh, H.-H. Carstensen, A.M. Dean, High-pressure rate rules for alkyl $+\mathrm{O}_{2}$ reactions. 2. The isomerization, cyclic ether formation, and $\beta$-scission reactions of hydroperoxy alkyl radicals, J. Phys. Chem. A, 116 (2012), 5068-5089

[73] S.M. Villano, H.-H. Carstensen, A.M. Dean, Rate rules, branching ratios, and pressure dependence of the $\mathrm{HO}_{2}+$ olefin addition channels, J. Phys. Chem. A, 117 (2013), 6458-6473

[74] E.R. Ritter, J.W. Bozzelli, THERM: thermodynamic property estimation for gas phase radicals and molecules, Int. J. Chem. Kinet., 23 (1991), 767-778

[75] S.W. Benson, Thermochemical kinetics, (second ed.)Wiley, New York (1976)

[76] S. Rolland, J.M. Simmie, The comparison of detailed chemical kinetic mechanisms; forward versus reverse rates with CHEMRev, Int. J. Chem. Kinet., 37 (2005), 119-125

[77] M. Pelucchi, K.P. Somers, K. Yasunaga, U. Burke, A. Frassoldati, E. Ranzi, H.J. Curran, T. Faravelli, An experimental and kinetic modeling study of the pyrolysis and oxidation of $n-C_{3}-C_{5}$ aldehydes in shock tubes, Combust. Flame, 162 (2015), 265-286

[78] A.W. Jasper, J.A. Miller, Lennard-Jones parameters for combustion and chemical kinetics modeling from fulldimensional intermolecular potentials, Combust. Flame, 161 (2014), 101-110

[79] W. Tsang, I.A. Awan, W.S. McGivern, J.A. Manion, "Soot precursor from real fuels: the unimolecular reaction of fuel radicals" in combustion generated fine carbonaceous particles, Proceedings of an International Workshop held in Villa Orlandi, Anacapri, KIT Scientific Publishing (2009) May 13-16, 2007 ed. vol. ISBN: 978-3-86644-441-6 
[80] R. Sivaramakrishnan, J.V. Michael, Rate Constants for $\mathrm{OH}$ with selected large alkanes: shock-tube measurements and an improved group scheme, J. Phys. Chem. A, 113 (2009), 5047-5060

[81] J. Aguilera-Iparraguirre, H.J. Curran, W. Klopper, J.M. Simmie, Accurate benchmark calculation of the reaction barrier height for hydrogen abstraction by the hydroperoxyl radical from methane. Implications for $\mathrm{C}_{n} \mathrm{H}_{2 \mathrm{n}+2}$ where $\mathrm{n}$ $=2 \rightarrow 4$, J. Phys. Chem. A, 112 (2008), 7047-7054

[82] K.A. Heufer, H. Olivier, Determination of ignition delay times of different hydrocarbons in a new high pressure shock tube, Shock Waves, 20 (2010), 307-316

[83] B.M. Gauthier, D.F. Davidson, R.K. Hanson, Shock tube determination of ignition delay times in full-blend and surrogate fuel mixtures, Combust. Flame, 139 (2004), 300-311

[84] CHEMKIN-PRO 15101, Reaction design, San Diego (2010)

[85] E.L. Petersen, R.K. Hanson, Nonideal effects behind reflected shock waves in a high-pressure shock tube Shock Waves, 10 (2001), 405-420

[86] M.F. Campbell, S. Wang, C.S. Goldenstein, R.M. Spearrin, A.M. Tulgestke, L.T. Zaczek, D.F. Davidson, R.K. Hanson Constrained reaction volume shock tube study of $n$-heptane oxidation: ignition delay times and time-histories of multiple species and temperature, Proc. Combust. Inst., 35 (2015), 231-239

[87] A. Jalan, I.M. Alecu, R. Meana-Pañeda, J. Aguilera-Iparraguirre, K.R. Yang, S.S. Merchant, D.G. Truhlar, W.H. Green New pathways for formation of acids and carbonyl products in low-temperature oxidation: the korcek decomposition of $\gamma$-ketohydroperoxides

J. Am. Chem. Soc., 135 (2013), 11100-11114 